\title{
Research on the Impact of Various Emission Reduction Policies on China's Iron and Steel Industry Production and Economic Level under the Carbon Trading Mechanism
}

\author{
Ye Duan ${ }^{1, *}$, Zenglin Han ${ }^{2}$, Hailin $\mathrm{Mu}^{3}$, Jun Yang ${ }^{4}$ and Yonghua $\mathrm{Li}^{1}$ \\ 1 College of Urban and Environmental, Liaoning Normal University, Dalian 116029, China; dydl@lnnu.edu.cn \\ 2 Center for Studies of Marine Economy and Sustainable Development, Liaoning Normal University, \\ Dalian 116029, China; hzl@Innu.edu.cn \\ 3 Key Laboratory of Ocean Energy Utilization and Energy Conservation of Ministry of Education, \\ Dalian University of Technology, Dalian 116024, China; hailinmu@dlut.edu.cn \\ 4 Human Settlements Research Center, Liaoning Normal University, Dalian 116029, China; \\ yangjun@lnnu.edu.cn \\ * Correspondence: dy200872083@mail.dlut.edu.cn
}

Received: 3 April 2019; Accepted: 23 April 2019; Published: 29 April 2019

\begin{abstract}
To study the emission reduction policies' impact on the production and economic level of the steel industry, this paper constructs a two-stage dynamic game model and analyzes various emission reduction policies' impact on the steel industry and enterprises. New results are observed in the study: (1) With the increasing emission reduction target (15\%-30\%) and carbon quota trading price (12.65-137.59 Yuan), social welfare and producer surplus show an increasing trend and emission macro losses show a decreasing trend. (2) Enterprises' reduction ranges in northwestern and southwestern regions are much higher than that of the other regions; the northeastern enterprise has the smallest reductions range. (3) When the market is balanced ( $0.8543-0.9320$ billion tons), the steel output has decreased and the polarization in various regions has been alleviated to some extent. The model is the abstraction and assumption of reality, which makes the results have some deviations. However, these will provide references to formulate reasonable emissions reduction and production targets. In addition, the government needs to consider the whole and regional balance and carbon trading benchmark value when deciding the implementation of a single or mixed policy. Future research will be more closely linked to national policies and gradually extended to other high-energy industries.
\end{abstract}

Keywords: carbon trading mechanism; emission reduction policy; China's iron and steel industry; a two-stage dynamic game

\section{Introduction}

The iron and steel industry (hereafter referred to as the steel industry) is an important fundamental industry of China's economy. After the founding of New China, the development of steel industry has gone through three stages. The first stage was from 1949 to 1960. The steel industry achieved rapid development under the influence of a "steel-oriented" mindset and the large-scale steelmaking movement, and steel output rose sharply. In the second stage, from 1960 to 1980, the development of the steel industry during this period was in a sluggish state. Many factors had brought about a huge negative impact on the development of the steel industry, causing the steel industry to stagnate. In the third stage, after the 1980s, the steel industry developed rapidly. The rank of annual output jumped to the top in the world in 1996. In recent years, the annual steel output has ranked first in the world, achieving a leap in the development of the steel industry. 
For a long time, the steel industry has provided important raw material guarantees for national construction, which has strongly supported the development of related industries, promoted the process of industrialization and modernization in China, and promoted the improvement of people's livelihood and social development.

Though the iron and steel industry has achieved remarkable achievements, it also faces many problems. The national steel industry equipment level is uneven, especially in terms of energy conservation and emission mitigation; a lot of debts of energy conservation and environmental protection investment were left over. Many enterprises have not achieved the comprehensive and stable discharge of pollutants; energy conservation and environmental protection facilities need to be further upgraded. Though the energy consumption and pollutant emissions of steel, per ton, have decreased in recent years, it cannot offset the increase in total energy consumption and pollutants caused by the increasing production. With the booming advancement of national industrialization and urbanization and the continuous upgrading of the consumption structure, the energy conservation and emission reduction work will become increasingly serious to the steel industry. At the same time, social development, ecological civilization construction, people's living needs, public opinion concerns, and more will impose new and more stringent requirements on energy conservation and emission reduction.

Obviously, for future development prospects, the steel industry still needs to make great efforts to adhere to green development, in addition to adhering to structural adjustment and innovation drive. It should aim to reduce energy consumption and pollutant emissions and to fully implement energy conservation and emission reduction. The government should keep on renovating, continuously optimizing the original fuel structure, vigorously developing the circular economy, actively researching and promoting green steel throughout the life cycle, and building a new pattern of steel manufacturing and social harmonious development.

At present, emission reduction policies such as the carbon trading mechanism or the carbon taxation mechanism have not been fully implemented. What are their impacts on the production level and economic profit of enterprises and the steel industry? Whether or not it is suitable for the actual situation of the steel industry is still unclear. Therefore, it is an urgent and difficult task for the steel industry to figure out the way to achieve green development in order to complete increasingly stringent emission reduction tasks.

In China, on 18th December, 2017, the National Development and Reform Commission announced the "National Carbon Emissions Trading Market Construction Plan (Power Generation Industry)," setting the threshold for China's power generation industry to be included in the carbon market: Annual emissions of 26,000 tons of carbon dioxide or above. It provides a reference for other industrial sectors, so this paper will study the carbon trading mechanism's impact on production level based on this program.

The remainder of this paper is organized as follows: In Section 2, a literature review focusing on the distribution mode and policy influence of carbon trading system is provided; in Section 3, a two-stage game theory modeling is constructed, and policy assumptions and data sources are provided; in Section 4, results and discussions are presented based on accounting data and statistical analysis; and in Section 5, conclusions and policy recommendations for China's iron and steel industry are drawn.

\section{Literature Review of Distribution Mode and Policy Influence of Carbon Trading System}

Dales [1] first proposed the concept of emissions trading, which aims to apply Coase's theorem of "efficiency in resource allocation through clear definition of rights" to water pollution control. In 2005, the European Union established the Emission Trading Scheme (ETS), covering more than 11,000 companies including manufacturing. The United States, the United Kingdom, and Australia have also established emission trading systems and exchanges. In China, although the "National Carbon Emissions Trading Market Construction Plan (Power Generation Industry)" was announced 
and the threshold for China's power generation industry to be included in the carbon market was set, the quota allocation method has not yet been announced. Moreover, the carbon market was only included in the power, cement, and electrolytic aluminum industries at the beginning, leaving the steel industry unincluded.

Scholars have studied the carbon trading mechanism from the perspectives of applicable industries, allocation, and influences. In the applicable industry research, most of the studies have been focused on the power industry where data and methods are relatively mature. Li and Colombier [2] analyzed the effects of different energy conservation and emission reduction policies on reducing carbon dioxide in the construction industry based on energy demand, population growth, and economic development trends. The results showed that the carbon emission trading mechanism has played a prominent role in improving the buildings' energy efficiency and energy-saving technologies' promotion. Anger [3], Chen and Tseng [4], and Alberola [5] discussed the application of carbon trading mechanisms in electricity, the manufacturing industry, and aviation. Considine and Larson [6] examined fuel switching in electricity production following the introduction of the European Union's Emissions Trading System (EU ETS) for greenhouse gas emissions. Shen et al. [7] used structural modeling methods to determine the factors affecting the carbon trading mechanisms' implementation in construction industry and explained the complex relationship between factors. In combination with the carbon footprint and the classic transportation model, Su [8] added carbon trading mechanism to the traditional three-level transportation network model and comprehensively analyzed the impact of carbon quotas and trading mechanisms on operating costs and transportation networks. Based on the Computable General Equilibrium (CGE) model, Zhang [9] studied the impact of China's establishment of carbon trading system on the construction industry.

Policy makers, economists, and researchers have different opinions on the issue of the allocation of quotas, due to their own situations. Ahman and Zetterberg [10] believed that, according to the different basic calculation data, the free distribution method can be divided into two distribution methods: Carbon emissions and production. However, the latter has higher data requirements than the former. Goeree et al. [11] believed that the free distribution method based on historical emissions as the basis for allocating quotas will lead to high carbon emission enterprises obtaining large quotas of carbon emission quotas due to historical data accounting, as well as raising quota prices in quota trading in the carbon market. Zetterberg et al. [12] suggested that the government should reward companies that have adopted emission reduction actions at the beginning of the carbon trading system, which will incentivize companies to obtain more quotas by increasing output. Grimm and Ilieva [13] believed that the allocation baseline for carbon emission rights will change over time and technology, so they cannot be allocated with reference to historical emissions data. For this reason, they proposed a scalable free allocation model. Wang and Wang [14] studied the carbon emission rights allocation in Beijing. They believed that distribution model combining free and auction is more suitable for China's national conditions. In the Emission Trading Scheme in Korea, Lee and Yu [15] observed the actual $\mathrm{CO}_{2}$ emission levels in the first compliance year and estimated the maximum and minimum emission levels by conducting a sensitivity analysis. They also estimated the surplus or deficit of emission permits during the first phase by comparing the estimated emission levels and the permit supply. Finally, they explored the supply and future prospects of offset credits, as well as the allocated permits. Guo, Chen, and Long [16] studied the initial quota allocation of the consuming government (based on the perspective of government and family evolutionary game) and found that when the government's evolutionary stability strategy is "strict policy," the family's evolutionary stabilization strategy will be affected by carbon reduction costs and purchasing carbon emission rights costs. Zhang, Li and Jia [17] established a Computable General Equilibrium (CGE) model to analyze the impact of different ETS quota allocation schemes on the electricity industry and determined the best choice of a quota allocation scheme for the electricity industry in China. The research on China's carbon trading market may provide an important case for the global carbon trading market. In the European Union's Emissions Trading System (EU ETS), Duscha [18] analyzed the demand for certificates from a reserve 
of about 400 million allowances under different assumptions on production development as well as different design options for Phase IV. The analysis was built on freely available allocation data from Phase III along with projections of production trends from different time periods in the past.

The impact of implementing carbon emission trading policies is mainly reflected by the impact on macroeconomic factors such as government welfare, emission reduction effects, and prices. Chen and $\mathrm{Wu}$ [19] constructed a model for the free allocation and sale of carbon allowances. The results showed that China's implementation of carbon emission trading can reduce the economic losses caused by $\mathrm{CO}_{2}$ emission reduction. Ellerman et al. [20] believed that developing countries can take full use of the new export chances brought about by carbon trading mechanisms to reap the benefits, while the countries with rich energy can have the largest revenues. Babiker M, Reilly J, and Viguier L [21] used CGE model to find that carbon emissions trading plays a negative role on social welfare. Wang, Chen, and Zou [22] found that carbon emission trading has a strong impact on prices. $\mathrm{CO}_{2}$ emission reduction policies can stimulate energy efficiency in the energy sector to reduce carbon emissions effectively. However, China's GDP growth and labor efficiency will be negatively affected. Jamasb and Kohler [23] used learning curve theory to find that carbon emission trading could play a role in updating and promoting energy-saving and emission-reducing technologies; they also found that the continuous popularization of energy-saving and emission-reducing technologies would, in turn, reduce carbon emission reduction costs. Aviyonah and Uhlmann [24] believed that environmental externalities could be measured by carbon trading prices, and carbon trading mechanisms can generate profits for companies that reduce $\mathrm{CO}_{2}$ emissions costs. Cong and Wei [25] studied the impact of power companies under different carbon trading allocation criteria and found that different allocations would also change carbon prices and electricity prices. Wu et al. [26] found that after the establishment of the carbon trading system, net exports of high-energy-consuming industries such as steel and electricity were greatly affected, and the power industry was even more affected. Li and Zhu [27] obtained the carbon emission trading's impact on high energy industries by constructing a partial equilibrium model of the three commodities in two countries and an emission reduction cost curve based on the micro level of technology. The results showed that in the carbon market with free quota allocation, carbon emission trading may cause distortion effects of non-backward capacity and backward production capacity. Wu, Fan, and Xia [28] used a multi-regional computable general equilibrium (CGE) model to analyze the economic impacts of ETS policy when combined with renewable energy sources (RES) policies in China. Dai, Xie, and Liu [29] used the CGE model to assess the carbon emissions trading's impact and renewable energy policies on economic contribution and to explore the influence of carbon trading volume, carbon price, and emission limits on the GDP in different sectors. Using the real trading data from the EU carbon market, Liu, Gao, and Guo [30] constructed a network model by integrating time windows with the network model; three types of network features were examined. The growth pattern of the carbon trading network was analyzed. Fernández et al. [31] analyzed the effectiveness of the carbon market as a basic tool in the reduction of emissions. The analysis also included other overlapping policies aimed at fighting climate change- - the promotion of renewables, for example.

On the study of the comparison and selection of carbon tax and carbon trading, it could be found that domestic and foreign scholars have not reached a consensus. Aviyonah and Uhlmann [24] argued that the carbon tax mechanism is easier to implement than the carbon trading mechanism because carbon trading mechanisms face the challenge of setting emission reduction targets. Mann [32] contended that a carbon tax policy is more important because carbon tax has the advantages of a simple implementation, a favorable emission reduction path for enterprises, and a small space for local governments to implement local protectionism. Wang et al. [33] believed that in the short term, the carbon trading mechanism is more cost-effective because of the higher cost in $\mathrm{CO}_{2}$ emission reduction technology.

For ease of reference, the references and summary information involved in this section are shown in Table 1. 
Table 1. References and summary information about the carbon trading mechanism involved in this section.

\begin{tabular}{|c|c|c|}
\hline \multicolumn{3}{|r|}{ Applicable industries } \\
\hline Year & Researcher & Industrial sector \\
\hline 2009 & $\mathrm{Li}$ and Colombier & construction \\
\hline 2010 & Anger & electricity \\
\hline 2008 & Chen and Tseng & manufacturing industry \\
\hline 2009 & Alberola & aviation \\
\hline 2012 & Considine and Larson & electricity \\
\hline 2016 & Shen et al. & construction \\
\hline 2017 & $\mathrm{Su}$ & transportation \\
\hline 2017 & Zhang & construction \\
\hline \multicolumn{3}{|r|}{ Allocation } \\
\hline Year & Researcher & Main ideas \\
\hline 2007 & Ahman and Zetterberg & $\begin{array}{l}\text { Free distribution method can be divided into two distribution methods: } \\
\text { Carbon emissions and production. }\end{array}$ \\
\hline 2010 & Goeree et al. & $\begin{array}{c}\text { Free distribution method based on historical emissions will lead to high } \\
\text { carbon emission enterprises to obtain large quotas of carbon emission quotas } \\
\text { and raise quota prices. }\end{array}$ \\
\hline 2012 & Zetterberg et al. & $\begin{array}{l}\text { The government should reward companies that have adopted emission } \\
\text { reduction actions at the beginning of the carbon trading system. }\end{array}$ \\
\hline 2013 & Grimm and Ilieva & $\begin{array}{l}\text { Allocation baseline will change over time and technology, cannot be allocated } \\
\text { with reference to historical emissions data. }\end{array}$ \\
\hline 2014 & Wang & $\begin{array}{l}\text { Distribution model combining free and auction is more suitable for China's } \\
\text { national conditions. }\end{array}$ \\
\hline 2017 & Lee and $\mathrm{Yu}$ & Permits were either in surplus or insufficient, depending on the sub-sector. \\
\hline 2018 & Guo, Chen, and Long & $\begin{array}{l}\text { When the government's evolutionary stability strategy is "strict policy," the } \\
\text { family's evolutionary stabilization strategy will be affected by the cost of } \\
\text { carbon reduction. }\end{array}$ \\
\hline 2018 & Zhang, Li and Jia & $\begin{array}{l}\text { Different quota allocation schemes have impacts on electricity price, and } \\
\text { there are some spillover effects to other industries. }\end{array}$ \\
\hline 2018 & Duscha & $\begin{array}{l}\text { Amount of allowances foreseen for dynamic allocation is sufficient for Phase } \\
\text { IV in the European Union's Emissions Trading System (EU ETS). }\end{array}$ \\
\hline \multicolumn{3}{|c|}{ Impact of implementing carbon emission trading policies } \\
\hline Year & Researcher & Main effect \\
\hline 1998 & Chen and $\mathrm{Wu}$ & Reduce the economic losses caused by $\mathrm{CO}_{2}$ emission reduction. \\
\hline 1998 & Ellerman et al. & Gain new export opportunities to reap the benefits. \\
\hline 2004 & $\begin{array}{l}\text { Babiker M, Reilly J, and } \\
\text { Viguier L }\end{array}$ & Negative impact on the social welfare. \\
\hline 2005 & Wang, Chen, and Zou & $\begin{array}{l}\text { A strong impact on production and prices. However, China's GDP growth } \\
\text { and labor efficiency will be negatively affected. }\end{array}$ \\
\hline 2007 & Jamasb and Kohler & Update and promote energy-saving and emission-reducing technologies. \\
\hline 2009 & $\begin{array}{l}\text { Aviyonah and } \\
\text { Uhlmann }\end{array}$ & Generate profits for companies that reduce $\mathrm{CO} 2$ emissions costs. \\
\hline 2010 & Cong and Wei & Change carbon prices and electricity prices. \\
\hline 2015 & $\mathrm{Wu}$, Fan, and Xia et al. & Net exports of high-energy-consuming industries were greatly affected. \\
\hline 2017 & $\mathrm{Li}$ and $\mathrm{Zhu}$ & $\begin{array}{c}\text { Cause distortion effects of non-backward capacity and backward } \\
\text { production capacity. }\end{array}$ \\
\hline 2017 & Wu, Fan and Xia & $\begin{array}{l}\text { The combination of an ETS and a feed-in tariff (FIT) results in greater GDP } \\
\text { cost and welfare loss in all Chinese regions }\end{array}$ \\
\hline 2018 & Dai, Xie, and Liu et al. & $\begin{array}{l}\text { Contributes to the achievement of emission reduction targets with less } \\
\text { economic cost }\end{array}$ \\
\hline 2018 & Liu, Gao and Guo & $\begin{array}{l}\text { As the market grows, the geodesic distances become shorter and the } \\
\text { clustering coefficients become larger. }\end{array}$ \\
\hline 2018 & Fernández. et al. & $\begin{array}{l}\text { EU-ETS is effective to reduce emissions, and each phase has a greater impact } \\
\text { on the reduction. }\end{array}$ \\
\hline
\end{tabular}


Through the literature review of emission reduction policies, especially carbon trading mechanisms, we can find that the macroeconomic energy and economic model can be used to calculate carbon trading quotas, carbon prices, and other values, which can better analyze the impact on the economy, environment, and emission reduction. However, most of this research was conducted from a macro perspective, and there is less literature on using game theory to study the mutual decision-making and emission reduction mechanism between the industry and enterprises from both microscopic and macroscopic perspective. There is also relatively less research literature on the integration of policies such as mechanisms into the emission reduction model and the comparison of single and mixed emission reduction policies. With the continuous economy development and the constant attention of environmental concerns, emission mitigation pressure will increase continuously. An individual carbon emission reduction policy cannot meet the needs of national economic development and emission mitigation. Carbon capture and storage (CCS), carbon sinks, and other significant reductions methods are possible to be integrated into the overall mitigation system. There are few papers on relevant game theory, and, as such, more research needs to be introduced. In addition, China has not yet started the carbon tax mechanism, and the official has not formulated detailed implementation plans. Therefore, this paper uses the carbon trading mechanism as the background of emission reduction policies to conduct corresponding policy research and analysis.

Secondly, we find that researchers have usually focused on national level and entire sectors (industry, service industry, agriculture). Research on a provincial level or a single industry department are few. The iron and steel industry is a basic industry and one of the most $\mathrm{CO}_{2}$-emitting heavy industrial sectors, which needs to do some further important emission reduction tasks research.

Thirdly, the model gives priority to the literature while giving less focus to empirical analysis in the previous research, and the parameters usually derive from the existing data of developed countries. The study of two typical enterprises is the most classic. In China, there are significant regional differences and economic development imbalances, and these areas' steel industry information and parameters need to be supplemented.

Above all, the reasonable $\mathrm{CO}_{2}$ emission reduction policy will be the core issue in this paper. Therefore, this paper organizes the six main areas' steel industry's energy, environment, and economic data. Integrated with the government corresponding long-term plan, the carbon trading mechanism-including production subsidies, $\mathrm{CCS}$, and $\mathrm{CO}_{2}$ external losses-is included in this research; then, a two-stage dynamic game model is constructed. Using the background of different carbon emissions' decreased demand, we discuss game behavior in different regions under different reduction targets; and, finally, we investigate different emissions reduction scenarios' effect and economic impact.

\section{Methods}

\subsection{Notations and Explanations}

As shown in Figure 1, according to the regional division of China, China is divided into six regions: North China (i.e., (1) Beijing, (2) Tianjin, (3) Hebei, (4) Shanxi, and (5) Inner Mongolia), Northeast China (i.e., (6) Liaoning, (7) Jilin, and (8) Heilongjiang), East China (i.e., (9) Shanghai, (10) Jiangsu, (11) Zhejiang, (12) Anhui, (13) Fujian, (14) Jiangxi, (15) Shandong, and (22) Taiwan), South Central China (i.e., (16) Henan, (17) Hubei, (18) Hunan, (19) Guangdong, (20) Guangxi, (21) Hainan, (3) Hong Kong, and (34) Macau), Southwest China (i.e., (22) Chongqing, (23) Sichuan, (24) Guizhou, (25) Yunnan, and (31) Tibet), Northwest China (i.e., (26) Shaanxi, (27) Gansu, (28) Qinghai, (29) Ningxia, and (30) Xinjiang). For data reasons, Tibet, Hong Kong, Macau, and Taiwan are not included. In this paper, regions are presented by subscripts: 1 represents North China, 2 represents Northeast China, and so on. 


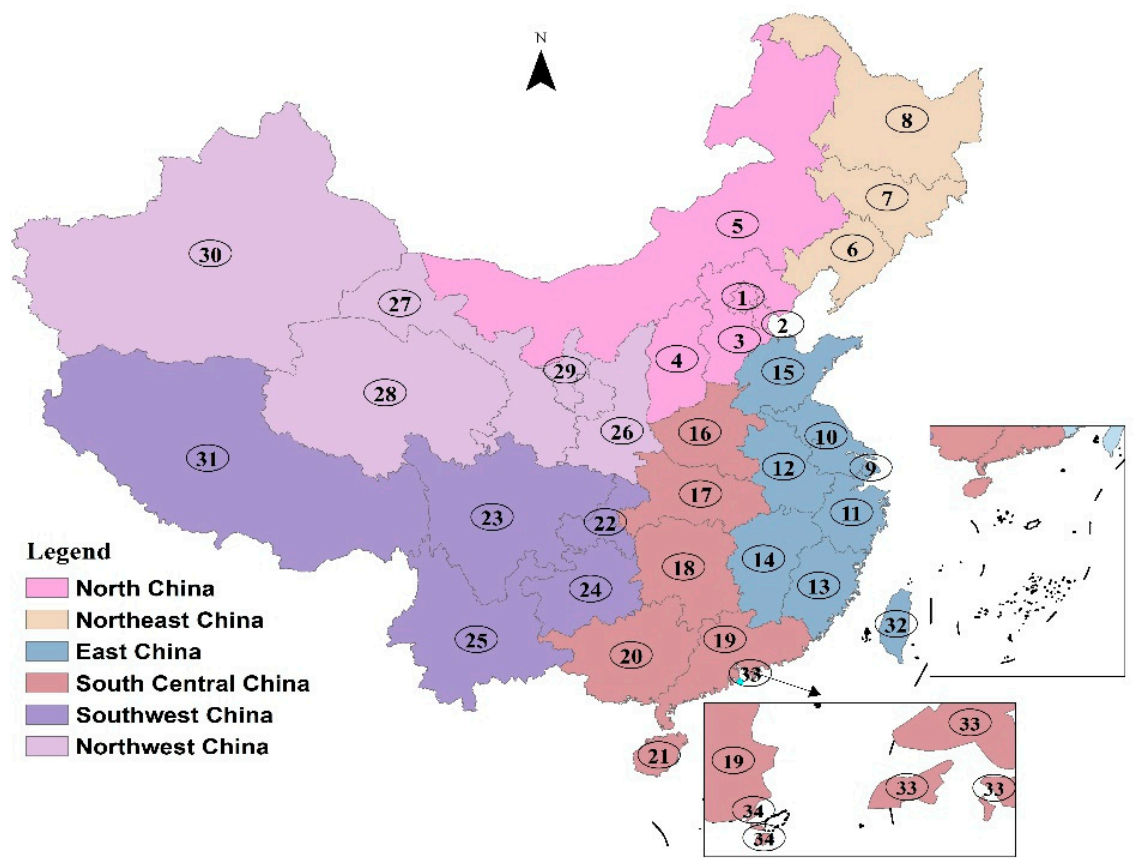

Figure 1. Regional division of China in this paper.

Consistent with the game sequence described in the literature of Duan et al. [34], the main research focus of this paper includes the government and the above six regions, and the regional steel industry data is regarded as a steel enterprise entity. The government emissions reduction policy is a double game problem. Firstly, there is a decomposition game between the government and regional enterprises: The government stipulates the emissions reduction target for a certain period, after which the regional enterprises should determine their respective reduction ranges according to their own cost curves. Secondly, there is a game of product output between the six regions, and the different targets of the regional enterprises will affect their respective output levels and market competitiveness. Therefore, the resultant game order is as follows: In the first stage, the government sets corresponding reduction targets and reduction policies (e.g., emissions allowances, product subsidies, CCS, independent or mixed); in the second stage, on the premise of guaranteeing profit maximization, the regional enterprises choose their respective reduction targets and output levels simultaneously. Based on this idea, this paper adopts the inverse method to solve the two-stage game problem. The notations used in this paper and their explanations are presented in Table 2. The main hypothesis of this paper is basically consistent with the hypothesis of Duan et al. [34].

Table 2. Notations and explanations used in this paper.

\begin{tabular}{cc}
\hline Notations & Explanations \\
\hline$Q$ & Steel production \\
$P$ & The price of steel \\
$\alpha$ & The constant of the market inverse demand curve \\
$\beta$ & The primary coefficient of the market inverse demand curve \\
$q_{i}$ & Steel production of region $i$ \\
$e_{2015, i}$ & The region $i \mathrm{CO}_{2}$ emission intensity of per ton steel in 2015 \\
$e_{i}$ & The region $i \mathrm{CO}_{2}$ emission intensity of per ton steel at some stage \\
$r_{i}$ & The decline range of $\mathrm{CO}_{2}$ emission intensity of per ton steel in region $i$ at some stage \\
$R$ & The decline target of national $\mathrm{CO}_{2}$ emission intensity of per ton steel at some stage \\
$M A C$ & Marginal abatement cost curve in iron and steel industry \\
$a_{i}$ & The quadratic coefficient of steel industry's MAC in region $i$ \\
$b_{i}$ & The primary coefficient of steel industry's MAC in region $i$ \\
\hline
\end{tabular}


Table 2. Cont.

\begin{tabular}{cc}
\hline Notations & Explanations \\
\hline$C_{i}$ & The cost function of steel industry in region $i$ \\
$C_{0, i}$ & The production cost of steel industry in region $i$ \\
$c_{i}$ & The cost of base period emission reduction in region $i$ \\
$e_{0}$ & Carbon trading benchmarks \\
$P P$ & Purchase price of carbon quota \\
$S P$ & Selling price of carbon quota \\
$C Q_{i}$ & Carbon quota of region $i$ \\
$W$ & Social welfare function \\
$C S$ & Consumer surplus \\
$P S$ & Producer surplus \\
$D(E)$ & Total macro external environment loss of $\mathrm{CO}_{2}$ emission \\
$\theta$ & The external loss parameter of $\mathrm{CO}_{2}$ \\
$\eta$ & The production subsidies \\
$m$ & The $\mathrm{CO}_{2}$ emission reduced by CCS demonstration project \\
$A$ & The primary coefficient of CCS demonstration project cost curve \\
$B$ & The constant of CCS demonstration project cost curve \\
$\pi_{i}$ & The profit function of steel industry in region $i$ \\
$E$ & The total CO $\mathrm{O}_{2}$ emissions in iron and steel industry \\
$S$ & The total subsidy \\
$M$ & The total cost of CCS demonstration project \\
\hline
\end{tabular}

\subsection{Scenario Assumptions}

For future development direction of steel industry and $\mathrm{CO}_{2}$ emission reduction targets, the relevant development plans are mostly based on textual qualitative language, and the description of clear emission reduction policies is rather vague. Due to the uncertainty of the policy and the combing of the literature, this paper establishes a model of enterprise output selection under the carbon trading mechanism, studies the impact of future government (steel industry) emission reduction policies on the economic, environmental, and other factors of enterprises and the steel industry, and focuses on the trends of various economic and environmental indicators.

\subsubsection{Case 1: Only Carbon Trading Scenarios}

Recently, due to policy and technology constraints, the carbon trading mechanism is the only policy-based emission reduction measure to achieve emission reduction targets. The government (steel industry) sets $\mathrm{CO}_{2}$ emission allowances for production enterprises, and enterprises buy or sell their quotas in the market. To prevent corporate speculation, this paper stipulates that the subsidy value is not greater than the enterprise purchase quota expenditure, and the time is set to 2020.

\subsubsection{Case 2: Mixed Policy Scenario, Carbon Trading and Subsidy}

When emission reduction targets continue to increase, steel companies that purchase carbon emission allowances will face increasing pressure to reduce emissions and purchase quotas, which will severely compress producers' profit margins. At this time, the rebate subsidy based on product output for enterprises purchasing carbon emission quota can improve their production enthusiasm and capacity. To prevent corporate speculation, this paper stipulates that the subsidy value is not greater than the enterprise purchase quota expenditure, and the time is set to 2025. 


\subsubsection{Case 3: Mixed Policy Scenario, Carbon Trading, Subsidy, and CCS}

When the emission reduction targets gradually increase, the implementation of carbon trading and subsidies may not fully meet the $\mathrm{CO}_{2}$ emission reduction target. CCS, which will play as a large-scale $\mathrm{CO}_{2}$ emission reduction role, will be put into operation in the medium and long term. This research assumes that all subsidies are provided by the government (steel industry). To prevent corporate speculation, this paper stipulates that the subsidy value is not greater than the enterprise purchase quota expenditure, and the time is set to 2030. The government invests in the construction of one or two demonstration projects that can absorb millions of tons of $\mathrm{CO}_{2}$.

\subsection{The Two-Stage Dynamic Game Solving Process}

Regional enterprises will face the given government emission mitigation targets and corresponding policies in the second stage, and select the decline in production output and emission intensity. The profit function in different situations is as follows:

$$
\begin{aligned}
\pi_{\text {casel }, i} & =P(Q) q_{i}-C_{i} q_{i}=(\alpha-\beta Q) q_{i}-q_{i} C_{0, i}-q_{i} \lambda\left(c_{i}+\int_{0}^{r_{i}} M A C_{i}(r) d r\right)+C T_{i} \\
& =(\alpha-\beta Q) q_{i}-q_{i} C_{0, \text { casel }, i}-q_{i} \lambda\left(c_{i}+\int_{0}^{r_{i}} M A C_{i}(r) d r\right)+C T_{i}
\end{aligned}
$$

Among them, $C T_{i}=\left\{\begin{array}{l}S P \cdot\left[e_{0}-e_{2015, i}\left(1-r_{i}\right)\right] \cdot q_{i} \text {, when } e_{0} \geq e_{2015, i}\left(1-r_{i}\right) \\ P P \cdot\left[e_{0}-e_{2015, i}\left(1-r_{i}\right)\right] \cdot q_{i} \text {, when } e_{0}<e_{2015, i}\left(1-r_{i}\right)\end{array}\right.$.

$$
\begin{aligned}
\pi_{\text {case } 2, i} & =P(Q) q_{i}-C_{i} q_{i}=(\alpha-\beta Q) q_{i}-q_{i} C_{0, i}-q_{i} \lambda\left(c_{i}+\int_{0}^{r_{i}} M A C_{i}(r) d r\right)+C T_{i}+\eta k_{i} q_{i} \\
& =(\alpha-\beta Q) q_{i}-q_{i} C_{0, \text { case } 2, i}-q_{i} \lambda\left(c_{i}+\int_{0}^{r_{i}} M A C_{i}(r) d r\right)+C T_{i}+\eta k_{i} q_{i}
\end{aligned}
$$

which, $C T_{i}=\left\{\begin{array}{l}S P \cdot\left[e_{0}-e_{2015, i}\left(1-r_{i}\right)\right] \cdot q_{i} \text {, when } e_{0} \geq e_{2015, i}\left(1-r_{i}\right) \\ P P \cdot\left[e_{0}-e_{2015, i}\left(1-r_{i}\right)\right] \cdot q_{i} \text {, when } e_{0}<e_{2015, i}\left(1-r_{i}\right)\end{array}, k_{i}=\left\{\begin{array}{c}0, \text { when } e_{0} \geq e_{2015, i}\left(1-r_{i}\right) \\ 1, \text { when } e_{0}<e_{2015, i}\left(1-r_{i}\right)\end{array}\right.\right.$.

$$
\begin{aligned}
\pi_{\text {case } 3, i} & =P(Q) q_{i}-C_{i} q_{i}=(\alpha-\beta Q) q_{i}-q_{i} C_{0, i}-q_{i} \lambda\left(c_{i}+\int_{0}^{r_{i}} M A C_{i}(r) d r\right)+C T_{i}+\eta k_{i} q_{i} \\
& =(\alpha-\beta Q) q_{i}-q_{i} C_{0, \text { case } 3, i}-q_{i} \lambda\left(c_{i}+\int_{0}^{r_{i}} M A C_{i}(r) d r\right)+C T_{i}+\eta k_{i} q_{i}
\end{aligned}
$$

which, $C T_{i}=\left\{\begin{array}{l}S P \cdot\left[e_{0}-e_{2015, i}\left(1-r_{i}\right)\right] \cdot q_{i} \text {, when } e_{0} \geq e_{2015, i}\left(1-r_{i}\right) \\ P P \cdot\left[e_{0}-e_{2015, i}\left(1-r_{i}\right)\right] \cdot q_{i} \text {, when } e_{0}<e_{2015, i}\left(1-r_{i}\right)\end{array}, k_{i}=\left\{\begin{array}{c}0, \text { when } e_{0} \geq e_{2015, i}\left(1-r_{i}\right) \\ 1, \text { when } e_{0}<e_{2015, i}\left(1-r_{i}\right)\end{array}\right.\right.$.

Each enterprise faces different profit functions because of different emission levels. In case 2 and case 3, the government subsidizes enterprises that purchase carbon quotas and does not subsidize enterprises which sell carbon quotas. When solving, it is necessary to comprehensively consider the relationship between the emission intensity and the reference value to determine whether the enterprise enjoys subsidies, and then determines the profit function of the enterprise.

Let $\frac{\partial \pi_{i}}{\partial q_{i}}=0$ and $\frac{\partial \pi_{i}}{\partial r_{i}}=0$, the corresponding reduction range of emission intensity $r_{i}$ and output $q_{i}$ of iron and steel enterprises in each region can be obtained.

In different cases, the social welfare function has been expanded, the specific form is as follows:

$$
\begin{aligned}
W_{\text {Case } 1} & =C S+P S-D(E)=\int_{0}^{Q} P(q) d q-P(Q) Q+\sum_{i=1}^{6} \pi_{\text {case } 1, i}-\theta E \\
& =\int_{0}^{Q}(\alpha-\beta q) d q-\left(\alpha-\beta \sum_{i=1}^{6} q_{i}\right) \sum_{i=1}^{6} q_{i}+\sum_{i=1}^{6} \pi_{\text {case } 1, i}-\theta \sum_{i=1}^{6} e_{2015, i}\left(1-r_{i}\right) q_{i}
\end{aligned}
$$




$$
\begin{aligned}
W_{\text {Case } 2} & =C S+P S-S-D(E)=\int_{0}^{Q} P(q) d q-P(Q) Q+\sum_{i=1}^{6} \pi_{\text {case } 2, i}-\eta \sum_{i=1}^{6} k_{i} q_{i}-\theta E \\
& =\int_{0}^{Q}(\alpha-\beta q) d q-\left(\alpha-\beta \sum_{i=1}^{6} q_{i}\right) \sum_{i=1}^{6} q_{i}+\sum_{i=1}^{6} \pi_{\text {case } 2, i}-\eta \sum_{i=1}^{6} k_{i} q_{i}-\theta \sum_{i=1}^{6} e_{2015, i}\left(1-r_{i}\right) q_{i} \\
W_{\text {Case } 3}=C S & +P S-S-D(E)-M=\int_{0}^{Q} P(q) d q-P(Q) Q+\sum_{i=1}^{6} \pi_{\text {case } 3, i}-\eta \sum_{i=1}^{6} k_{i} q_{i}-\theta E-(A m+B) \\
= & \int_{0}^{Q}(\alpha-\beta q) d q-\left(\alpha-\beta \sum_{i=1}^{6} q_{i}\right) \sum_{i=1}^{6} q_{i}+\sum_{i=1}^{6} \pi_{\text {case } 3, i}-\eta \sum_{i=1}^{6} k_{i} q_{i}-\theta \sum_{i=1}^{6} e_{2015, i}\left(1-r_{i}\right) q_{i}-(A m+B)
\end{aligned}
$$

In the first stage, 6 regions' enterprises obtain the corporate profit function by selecting the decline in their respective product output and emission intensity as a response to the government's corresponding emission reduction policy and emission reduction target $R$. The following relationship of government's decision can be obtained and expressed as:

Case 1

$$
\begin{aligned}
& \max W \\
& \text { s.t. }\left\{\begin{array}{l}
\frac{\sum_{i=1}^{6} e_{2015, i}\left(1-r_{i}\right) q_{i}}{\sum_{i=1}^{6} q_{i}}=e_{2010}(1-R) \\
0<r_{i}<1 \\
e_{i}>0 \\
q_{i}>0 \\
0 \leq S P \leq P P \\
i=1,2,3,4,5,6
\end{array}\right.
\end{aligned}
$$

Case 2

$$
\begin{aligned}
& \max W \\
& \qquad \begin{array}{l}
\frac{\sum_{i=1}^{6} e_{2015, i}\left(1-r_{i}\right) q_{i}}{\sum_{i=1}^{6} q_{i}}=e_{2010}(1-R) \\
0<r_{i}<1 \\
e_{i}>0 \\
q_{i}>0 \\
0 \leq S P \leq P P \\
\eta \geq 0 \\
0 \leq \frac{-\sum_{i=1}^{6} k_{i} \cdot P P \cdot\left[e_{0}-e_{2015, i}\left(1-r_{i}\right)\right] q_{i}}{\eta_{i} q_{i}} \\
k=0,1 \\
i=1,2,3,4,5,6
\end{array}
\end{aligned}
$$


Case 3

$$
\begin{aligned}
& \max W \\
& \text { s.t. }\left\{\begin{array}{l}
\frac{\sum_{i=1}^{6} e_{2015, i}\left(1-r_{i}\right) q_{i}-m}{\sum_{i=1}^{6} q_{i}}=e_{2010}(1-R) \\
0<r_{i}<1 \\
e_{i}>0 \\
q_{i}>0 \\
0 \leq 5 \leq P P \\
0 \leq \frac{\sum_{i=1}^{6} k_{i} q_{i}}{6} \\
\quad-\sum_{i=1}^{6} k_{i} \cdot P P \cdot\left[e_{0}-e_{2015, i}\left(1-r_{i}\right)\right] q_{i} \\
k=0,1 \\
1 \times 10^{6} \leq m \leq 2 \times 10^{6} \\
i=1,2,3,4,5,6
\end{array}\right.
\end{aligned}
$$

The equilibrium of production and emissions mitigation can be described by $S P, P P$, and $\eta$. Then, we put the production and emission reduction results determined by $S P, P P$, and $\eta$ into the first stage to get the expression formula of social economic welfare $(W)$. In the game's first stage, the government maximizes social economic welfare determined by $S P, P P$, and $\eta$. Finally, we get $W$ and other corresponding conclusions.

\subsection{Data Sources}

The statistics are from China Statistical Yearbook [35], China Industrial Statistical Yearbook [36], China Energy Statistical Yearbook [37], China Steel Yearbook [38], and the statistical yearbooks of various provinces. Relevant economic data are equivalent to comparable prices in 2010. The time span is from 2005 to 2016. In addition, $\mathrm{CO}_{2}$ emissions in industrial production (IPPU $\mathrm{CO}_{2}$ ), which also produces large amounts of $\mathrm{CO}_{2}$, are included in this paper.

Because of the data availability, the steel industry's relevant energy consumption and economic data are derived from the ferrous metal smelting and calendaring processing industry in the China Statistical Yearbook. The $\mathrm{CO}_{2}$ accounts of fossil energy consumption and IPPU refers to IPCC2006 [39] and Duan et al. [40].

\section{Results and Discussions}

\subsection{The Parameter Fitting's Results}

In this paper, referring to the research of $\mathrm{Ma}$ and $\mathrm{Li} \mathrm{[41],} \mathrm{the} \mathrm{market} \mathrm{demand} \mathrm{for} \mathrm{steel} \mathrm{industry} \mathrm{is}$ expressed by the apparent consumption, and the product price was obtained by dividing the industrial output value by the output. In the selection of the curve form, the inverse demand curve can be approximated as a straight line inclined to the lower right. The inverse demand curve fitting equation is as follows:

$$
P=\alpha-\beta Q=15769.56-1.13 \times 10^{-5} Q
$$

In 2010, $\mathrm{CO}_{2}$ emissions average level in steel industry was 3.1710 tons $\mathrm{CO}_{2}$ per ton of steel (the same below, omitted). In the calculation below, the base period data of each region is the basic data for 2015 unless otherwise specified. According to the collection and calculation, the average level of $\mathrm{CO}_{2}$ emission in 2015 was 2.8210. Correspondingly, the $\mathrm{CO}_{2}$ emission levels of the six regions in 2015 were $e_{1}=2.3344, e_{2}=3.5698, e_{3}=2.9040, e_{4}=2.8779, e_{5}=3.2202$, and $e_{6}=4.5864$. 
In this paper, China's steel industry $\mathrm{CO}_{2}$ emissions from 2005 to 2016 were calculated by a non-parametric method, the $\mathrm{CO}_{2}$ marginal abatement cost was estimated by shadow price, and then the marginal abatement cost curve (MACC) was obtained. The calculation method reference was made to the relevant literature of Duan et al. [42-44] (the data was updated to 2016 and the function form was slightly changed), and the quadratic form was selected as the regression equation of MACC. The relationship between the emission intensity reduction in each region and the $\mathrm{CO}_{2} \mathrm{MACC}$ is shown in Table 3. It should be pointed out that due to the estimation of shadow price, the error and uncertainty of the $\mathrm{CO}_{2}$ marginal abatement cost curve are increased, which leads to a certain distance between the calculated abatement cost and the real abatement cost. This paper uses $\lambda\left(c_{i}+\int_{0}^{r_{i}} M A C_{i}(r) d r\right)$ to represent the actual emission reduction cost; $\lambda$ is 0.5 , in order to reduce the error.

Table 3. Some parameter values.

\begin{tabular}{|c|c|c|c|c|c|c|c|c|}
\hline Notations & \multicolumn{2}{|c|}{ Unit } & $i=1$ & $i=2$ & $i=3$ & $i=4$ & $i=5$ & $i=6$ \\
\hline$e_{2015, i}$ & \multicolumn{2}{|c|}{$\mathrm{tCO}_{2} / \mathrm{t}$} & 2.3344 & 3.5698 & 2.9040 & 2.8779 & 3.2202 & 4.5864 \\
\hline$a_{i}$ & \multicolumn{2}{|c|}{-} & 11661 & 17208 & 16932 & 12952 & 6397.2 & 3485 \\
\hline$b_{i}$ & \multicolumn{2}{|c|}{-} & -169.76 & 8876.7 & -166.92 & 1483.6 & 502.52 & 421.13 \\
\hline$c_{i}$ & \multicolumn{2}{|c|}{ Yuan } & 2168.2 & 3511.1 & 2165.4 & 3325.1 & 2368.7 & 3814.3 \\
\hline \multirow{4}{*}{$C_{0,2015, i}$} & \multirow{4}{*}{ Yuan } & 2015 & 2833.15 & 4898.47 & 3453.53 & 4153.15 & 3799.03 & 3832.38 \\
\hline & & 2020 & 2124.86 & 3918.77 & 2590.15 & 2491.89 & 3609.08 & 3640.76 \\
\hline & & 2025 & 1699.89 & 2743.14 & 2072.12 & 1868.92 & 3067.72 & 3094.64 \\
\hline & & 2030 & 1444.91 & 2194.51 & 1761.30 & 1588.58 & 2454.17 & 2475.71 \\
\hline
\end{tabular}

Through the combing of relevant policy documents, the future economic development goals of China's iron and steel industry and target of energy conservation and $\mathrm{CO}_{2}$ emission mitigation have been designated as mostly textual narratives, and there are basically no quantitative indicators of data. Accurately predicting future steel industry emission reduction targets, product yields, and development levels is impractical. Based on this, the focus of this paper is to explore the influence of implementation of different emission mitigation policies combination in China's steel industry's social welfare (W), consumer surplus (CS), producer surplus (PS), output, and total $\mathrm{CO}_{2}$ emissions, as well as the enterprise's output, profits, $\mathrm{CO}_{2}$ emissions, and other economic and environmental factors.

In the setting of the $\mathrm{CO}_{2}$ emission intensity reduction target, this paper refers to target of reducing the comprehensive energy consumption of ton steel by 12 kgce in 2020 (Steel Industry Adjustment and Upgrade Plan (2016-2020)). The target of 2020 is about $85 \%$ of the energy consumption level in 2010. Therefore, this paper sets the $\mathrm{CO}_{2}$ emission intensity in 2020 to be $15 \%$ lower than that in 2010 . We will observe the reaction of output, profit, and emission intensity of iron and steel enterprises and industries when the emission reduction target under the condition of $15 \%-20 \%$. We set the $\mathrm{CO}_{2}$ emission intensity in 2025 to be $20 \%$ lower than that in 2010 and observed the reaction of output, profit, and emission intensity of iron and steel enterprises and industries when the emission reduction targe under the condition of $20 \%-25 \%$. We set the $\mathrm{CO}_{2}$ emission intensity in 2030 to be $25 \%$ lower than that in 2010 and observed the reaction of output, profit, and emission intensity of iron and steel enterprises and industries when the emission reduction target under the condition of $25 \%-30 \%$.

Referring to Li's research [45], the average production cost of the base period can be obtained by calculating the business (regional) operating costs and steel production. This paper assumes that by 2020, the production costs in North China, East China, and South Central China will decrease significantly, and the production costs in Northeast China, Southwest China, and Northwest China will decrease less. Then, the gap will be gradually narrowed. By 2030, North China, East China, and South Central China will be basically in the same cost range, and the Northeast, Southwest, and Northwest regions will be located in another cost range. The external macro-environmental loss parameters refer to the study of Guenno and Tiezzi [46], $\theta=14.55$ Yuan/ton $\mathrm{CO}_{2}$. In 2030, it is assumed that the steel industry will plan to build 1-2 million tons of government-funded demonstration projects. The cost 
curve refers to [47-50], and the linear curve is $M=204.96 m+11.53 \times 10^{6}, m \in\left[1 \times 10^{6}, 2 \times 10^{6}\right]$ ton. The unit is $R M B$. Since the relationship between $P P$ and $S P$ is not easy to determine, let $P P=S P$ in order to facilitate calculation; that is, when carbon trading is conducted between enterprises, the price used to purchase or sell unit quota is the same.

In the selection of the benchmark value of the carbon trading mechanism $e_{0}$, considering that China has just started to pilot the carbon trading mechanism, the steel industry emission benchmark value should not be set too high. After the system is mature, the benchmark value should be set strictly. Assume that the benchmark value for 2020 is 2.8210 tons of $\mathrm{CO}_{2} /$ per ton steel (the average $\mathrm{CO}_{2}$ emission intensity in 2015). The benchmark value for 2025 is 2.3782 (25\% lower than the national emission level in 2010). For 2030, it will be 2.2197 (30\% lower than the national emissions level in 2010).

The specific data simulation parameter settings are shown in Table 3.

\subsection{Empirical Analysis}

\subsubsection{Case 1 , in 2020 Scenario}

The carbon trading policy is the only emission mitigation policy. Detailed results are shown in Figures 2 and 3, Tables 4 and 5. When the emission reduction targets gradually increase from 15\% to $20 \%$, the transaction price of carbon emission allowance increases from 12.65 yuan/ton to 34.81 yuan/ton, which increases by 2.75 times. Total output, total social welfare (W), consumer surplus (CS), and producer surplus (PS) all show an upward trend, and the macro environmental damage caused by $\mathrm{CO}_{2}$ emissions shows a decreasing trend. The total output maintains at around 854 million tons, which is a drop of nearly $25 \%$ compared to the 1.135 billion tons of steel production in 2016 . This means that demands in the steel market declined significantly in 2020. As the emission reduction target gradually increases from $15 \%$ to $20 \%$, total output, $W, C S, P S$, and emission loss increase by $0.05 \%, 0.21 \%, 0.10 \%$, $0.34 \%$, and $-5.84 \%$, respectively.

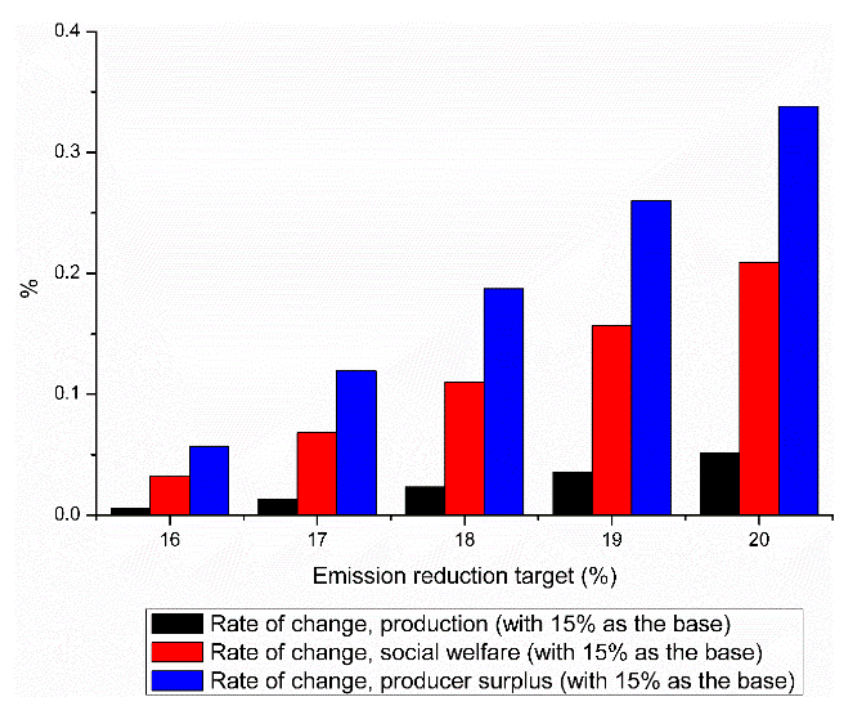

Figure 2. The rate of change of output, social welfare, and producer surplus under the carbon trading mechanism; take $15 \%$ as the baseline. 


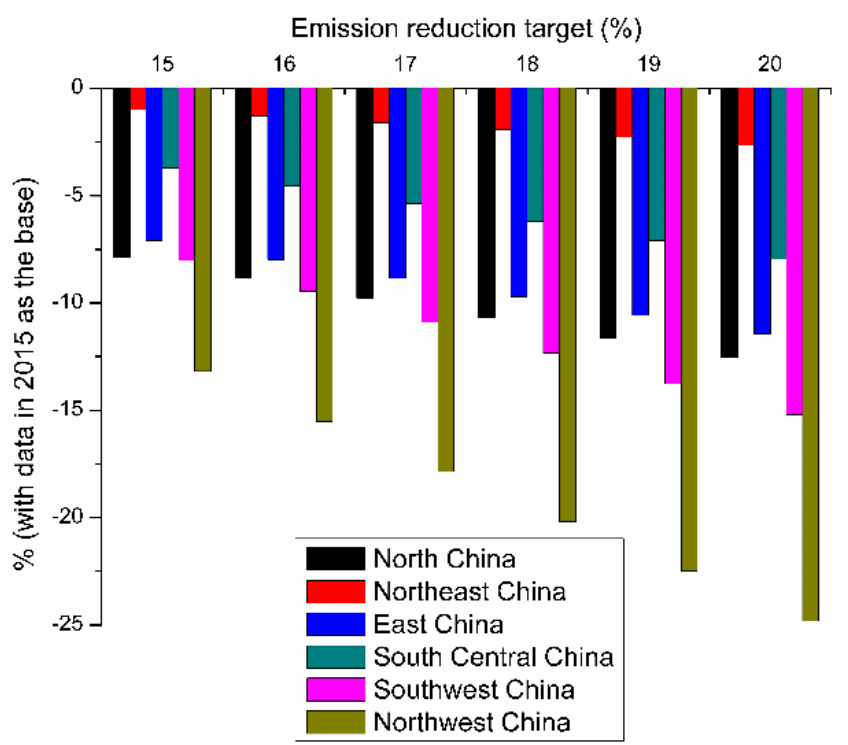

Figure 3. The change of regional emission intensity with the overall emission reduction target $(15 \%-20 \%$, carbon trade scenario only).

Table 4. The changes of the overall industry indicators under the carbon trade mechanism; the emission reduction target is $15 \%-20 \%$.

\begin{tabular}{ccccccc}
\hline Emission Reduction Target & $\mathbf{1 5 \%}$ & $\mathbf{1 6 \%}$ & $\mathbf{1 7 \%}$ & $\mathbf{1 8 \%}$ & $\mathbf{1 9 \%}$ & $\mathbf{2 0} \%$ \\
\hline Carbon quota transaction price (Yuan) & 12.65 & 16.28 & 20.30 & 24.74 & 29.57 & 34.81 \\
Production (100 million tons) & 8.5427 & 8.5432 & 8.5439 & 8.5447 & 8.5457 & 8.5471 \\
Rate of change, production (with 15\% as the base) & - & $0.01 \%$ & $0.01 \%$ & $0.02 \%$ & $0.04 \%$ & $0.05 \%$ \\
Rate of change, social welfare (with 15\% as the base) & - & $0.03 \%$ & $0.07 \%$ & $0.11 \%$ & $0.16 \%$ & $0.21 \%$ \\
Rate of change, producer surplus (with 15\% as the base) & - & $0.06 \%$ & $0.12 \%$ & $0.19 \%$ & $0.26 \%$ & $0.34 \%$ \\
\hline
\end{tabular}

Table 5. The changes of the various region enterprise indicators under the carbon trade mechanism; the emission reduction target is $15 \%-20 \%$.

\begin{tabular}{cccccccc}
\hline Emission Reduction Target & $\mathbf{1 5 \%}$ & $\mathbf{1 6 \%}$ & $\mathbf{1 7 \%}$ & $\mathbf{1 8 \%}$ & $\mathbf{1 9 \%}$ & $\mathbf{2 0 \%}$ \\
\hline & North China & 2.5841 & 2.5854 & 2.5869 & 2.5884 & 2.5900 & 2.5916 \\
& Northeast China & 0.3872 & 0.3864 & 0.3856 & 0.3847 & 0.3837 & 0.3827 \\
Production (100 & East China & 2.1673 & 2.1678 & 2.1684 & 2.1690 & 2.1696 & 2.1702 \\
million tons) & South Central China & 1.7405 & 1.7409 & 1.7413 & 1.7417 & 1.7422 & 1.7427 \\
& Southwest China & 1.1722 & 1.1723 & 1.1725 & 1.1726 & 1.1728 & 1.1730 \\
& Northwest China & 0.4915 & 0.4901 & 0.4886 & 0.4871 & 0.4856 & 0.4841 \\
\hline \multirow{2}{*}{$\begin{array}{c}\text { Rate of change, } \\
\text { North China }\end{array}$} & - & $0.11 \%$ & $0.23 \%$ & $0.36 \%$ & $0.50 \%$ & $0.65 \%$ \\
production (with 15\% & Northeast China & - & $-0.42 \%$ & $-0.91 \%$ & $-1.47 \%$ & $-2.11 \%$ & $-2.82 \%$ \\
as the base) & East China & - & $0.05 \%$ & $0.10 \%$ & $0.16 \%$ & $0.22 \%$ & $0.29 \%$ \\
& South Central China & - & $0.05 \%$ & $0.10 \%$ & $0.15 \%$ & $0.21 \%$ & $0.27 \%$ \\
& Southwest China & - & $0.02 \%$ & $0.05 \%$ & $0.09 \%$ & $0.13 \%$ & $0.18 \%$ \\
& Northwest China & - & $-0.59 \%$ & $-1.19 \%$ & $-1.80 \%$ & $-2.40 \%$ & $-2.98 \%$ \\
\hline \multirow{2}{*}{$\begin{array}{c}\text { The decline range of } \\
\text { emission intensity }\end{array}$} & North China & $-7.88 \%$ & $-8.83 \%$ & $-9.77 \%$ & $-10.71 \%$ & $-11.63 \%$ & $-12.55 \%$ \\
(with data in 2015 as & Northeast China & $-1.00 \%$ & $-1.28 \%$ & $-1.58 \%$ & $-1.92 \%$ & $-2.28 \%$ & $-2.66 \%$ \\
the base) & East China & $-7.10 \%$ & $-7.98 \%$ & $-8.85 \%$ & $-9.72 \%$ & $-10.58 \%$ & $-11.43 \%$ \\
& South Central China & $-3.71 \%$ & $-4.53 \%$ & $-5.36 \%$ & $-6.22 \%$ & $-7.09 \%$ & $-7.97 \%$ \\
& Southwest China & $-8.02 \%$ & $-9.46 \%$ & $-10.90 \%$ & $-12.34 \%$ & $-13.77 \%$ & $-15.20 \%$ \\
& Northwest China & $-13.18 \%$ & $-15.52 \%$ & $-17.85 \%$ & $-20.18 \%$ & $-22.50 \%$ & $-24.82 \%$ \\
\hline
\end{tabular}


To achieve the $15 \%-20 \%$ emission reduction target, enterprises in each region choose the emission intensity and output. As the emission reduction target increases, the emission intensity of Southwest China and Northwest China decreases more. When the industry emission reduction target is $20 \%$, the Northwest region's emission reduction rate reaches its maximum, which is $24.82 \%$; the East China and North China range is moderate, with a range of $7 \%-13 \%$; the emission reductions in the Northeast and South Central regions are small, and the Northeast is the smallest. For production, due to the different production costs and the impact of emission mitigation intensity, coupled with the implementation of the carbon trading policy, when the emission reduction targets grow, output of most regions has increased significantly, and only the steel production in Northeast China and Northwest China has declined. The output of the two regions has dropped significantly, which is approaching 3\%.

Under the premise emission reduction target of $15 \%-20 \%$ and 2.8210 tons $\mathrm{CO}_{2} /$ ton steel as the benchmark value, the $\mathrm{CO}_{2}$ emission intensity of North China, East China, and South Central China in the carbon trading market are lower than the benchmark value; they can choose to sell their carbon quota. The Northeast and Northwest regions have exceeded the benchmark value and need to purchase carbon quotas. For the Southwest region, when the emission reduction target is low $(15 \%-18 \%), \mathrm{CO}_{2}$ emission intensity is more than the benchmark and the enterprise needs to be purchased for the quotas; when the emission reduction target is high $(18 \%-20 \%)$ and $\mathrm{CO}_{2}$ emission intensity is lower than the benchmark value, the enterprise can choose to sell its own carbon quotas.

\subsubsection{Case 2, in 2025 Scenario}

The mixed emission mitigation policy includes carbon trading and subsidy policies. Detailed results are shown in Figures 4 and 5, Tables 6 and 7. Due to the strict emission benchmark values, the $\mathrm{CO}_{2}$ emission intensity of some regional enterprises cannot meet or fall below the benchmark value. The government needs to provide subsidies for enterprises with higher emission intensity. When the emission reduction targets gradually increase from $20 \%$ to $25 \%$, the transaction price of carbon emission allowance increases from 47.21 yuan/ton to 84.43 yuan/ton, an increase of 1.79 times. The value is maintained at around 15.5 yuan to 17 yuan.

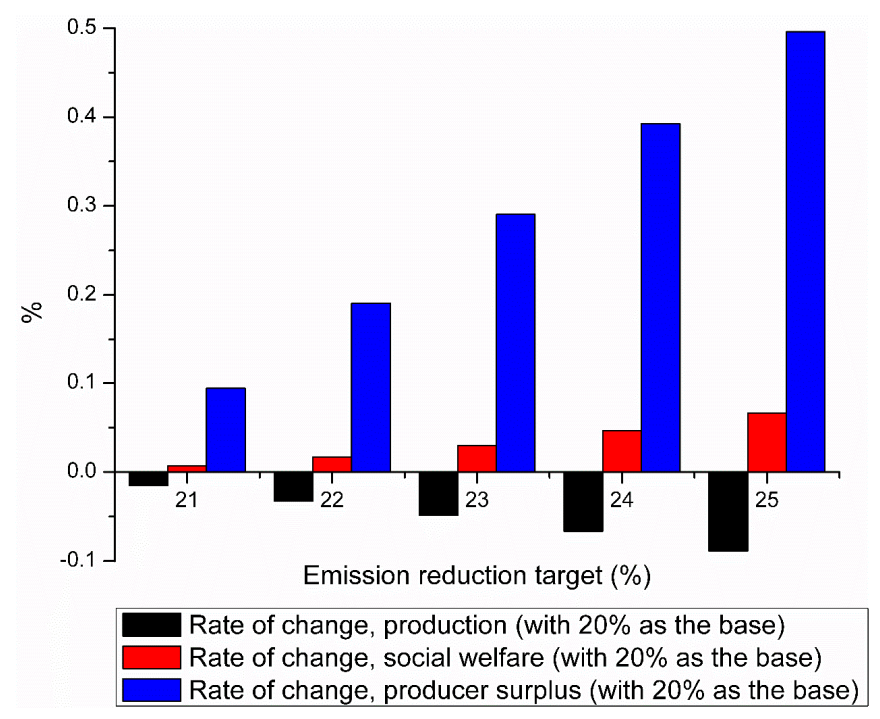

Figure 4. The rate of change of output, social welfare, and producer surplus under the carbon trading mechanism; take $20 \%$ as the baseline. 


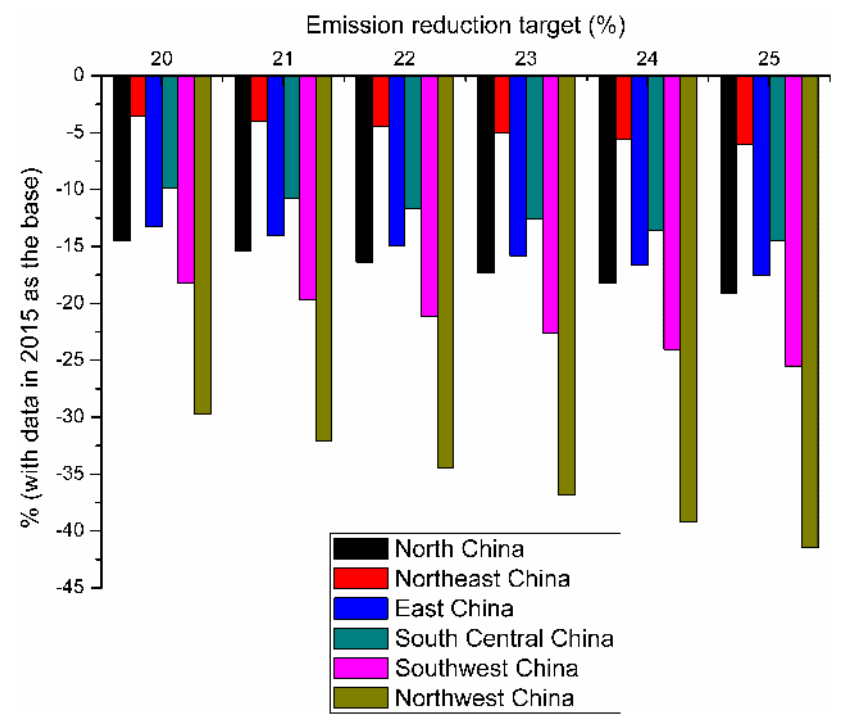

Figure 5. The change of regional emission intensity with the overall emission reduction target $(20 \%-25 \%$, carbon trade+ subsidy).

Table 6. The changes of the overall industry indicators under the carbon trade mechanism; the emission reduction target is $20 \%-25 \%$.

\begin{tabular}{ccccccc}
\hline Emission Reduction Target & $\mathbf{2 0} \%$ & $\mathbf{2 1 \%}$ & $\mathbf{2 2} \%$ & $\mathbf{2 3} \%$ & $\mathbf{2 4} \%$ & $\mathbf{2 5 \%}$ \\
\hline Carbon quota transaction price (Yuan) & 47.21 & 53.86 & 60.91 & 68.37 & 76.21 & 84.43 \\
Carbon quota transaction price (Yuan) & 9.0173 & 9.0159 & 9.0143 & 9.0129 & 9.0113 & 9.0093 \\
Unit value of subsidy (Yuan) & 17 & 17.5 & 17.5 & 17.5 & 17 & 15.5 \\
Rate of change, production (with 20\% as the base) & - & $-0.02 \%$ & $-0.03 \%$ & $-0.05 \%$ & $-0.07 \%$ & $-0.09 \%$ \\
Rate of change, social welfare (with 20\% as the base) & - & $0.01 \%$ & $0.02 \%$ & $0.03 \%$ & $0.05 \%$ & $0.07 \%$ \\
Rate of change, producer surplus (with 20\% as the base) & - & $0.09 \%$ & $0.19 \%$ & $0.29 \%$ & $0.39 \%$ & $0.50 \%$ \\
\hline
\end{tabular}

Table 7. The changes of the various region enterprise indicators under the carbon trade mechanism; the emission reduction target is $20 \%-25 \%$.

\begin{tabular}{|c|c|c|c|c|c|c|c|}
\hline \multicolumn{2}{|c|}{ Emission Reduction Target } & \multirow{2}{*}{$\begin{array}{c}20 \% \\
2.4863\end{array}$} & \multirow{2}{*}{$\begin{array}{c}\mathbf{2 1 \%} \\
2.4883\end{array}$} & \multirow{2}{*}{$\begin{array}{c}\mathbf{2 2} \% \\
2.4900\end{array}$} & \multirow{2}{*}{$\begin{array}{c}23 \% \\
2.4921\end{array}$} & \multirow{2}{*}{$\begin{array}{c}\mathbf{2 4 \%} \\
2.4942\end{array}$} & \multirow{2}{*}{$\begin{array}{c}25 \% \\
2.4963\end{array}$} \\
\hline \multirow{6}{*}{$\begin{array}{l}\text { Production (100 } \\
\text { million tons) }\end{array}$} & North China & & & & & & \\
\hline & Northeast China & 0.9253 & 0.9231 & 0.9209 & 0.9185 & 0.9160 & 0.9134 \\
\hline & East China & 2.1506 & 2.1511 & 2.1517 & 2.1521 & 2.1526 & 2.1531 \\
\hline & South Central China & 1.8143 & 1.8145 & 1.8149 & 1.8152 & 1.8154 & 1.8156 \\
\hline & Southwest China & 1.1706 & 1.1707 & 1.1710 & 1.1712 & 1.1715 & 1.1717 \\
\hline & Northwest China & 0.4702 & 0.4686 & 0.4673 & 0.4659 & 0.4646 & 0.4634 \\
\hline \multirow{6}{*}{$\begin{array}{l}\text { Rate of change, } \\
\text { production (with } 20 \% \\
\text { as the base) }\end{array}$} & North China & - & $0.15 \%$ & $0.32 \%$ & $0.49 \%$ & $0.68 \%$ & $0.90 \%$ \\
\hline & Northeast China & - & $-0.48 \%$ & $-1.01 \%$ & $-1.58 \%$ & $-2.21 \%$ & $-2.91 \%$ \\
\hline & East China & - & $0.05 \%$ & $0.09 \%$ & $0.14 \%$ & $0.17 \%$ & $0.19 \%$ \\
\hline & South Central China & - & $0.03 \%$ & $0.06 \%$ & $0.09 \%$ & $0.10 \%$ & $0.10 \%$ \\
\hline & Southwest China & - & $0.04 \%$ & $0.08 \%$ & $0.12 \%$ & $0.17 \%$ & $0.20 \%$ \\
\hline & Northwest China & - & $-0.60 \%$ & $-1.17 \%$ & $-1.67 \%$ & $-2.11 \%$ & $-2.52 \%$ \\
\hline \multirow{6}{*}{$\begin{array}{l}\text { The decline range of } \\
\text { emission intensity } \\
\text { (with data in } 2015 \text { as } \\
\text { the base) }\end{array}$} & North China & $-14.49 \%$ & $-15.43 \%$ & $-16.36 \%$ & $-17.29 \%$ & $-18.21 \%$ & $-19.13 \%$ \\
\hline & Northeast China & $-3.55 \%$ & $-4.02 \%$ & $-4.51 \%$ & $-5.01 \%$ & $-5.54 \%$ & $-6.08 \%$ \\
\hline & East China & $-13.23 \%$ & $-14.09 \%$ & $-14.96 \%$ & $-15.81 \%$ & $-16.67 \%$ & $-17.52 \%$ \\
\hline & South Central China & $-9.85 \%$ & $-10.77 \%$ & $-11.69 \%$ & $-12.62 \%$ & $-13.55 \%$ & $-14.47 \%$ \\
\hline & Southwest China & $-18.22 \%$ & $-19.69 \%$ & $-21.14 \%$ & $-22.60 \%$ & $-24.05 \%$ & $-25.49 \%$ \\
\hline & Northwest China & $-29.72 \%$ & $-32.09 \%$ & $-34.45 \%$ & $-36.81 \%$ & $-39.15 \%$ & $-41.48 \%$ \\
\hline
\end{tabular}

The total output, consumer surplus, and macro environmental damage caused by $\mathrm{CO}_{2}$ emissions have decreased, and the overall social welfare and producer surplus have shown an upward trend. This shows that, although the emission reduction target has become increasingly severe, the behavior 
of returning subsidies to enterprises has increased the production enthusiasm of producers and helps to increase corporate profits. The total output has remained at around 900 million tons. Though the emission reduction target has increased, the total output has increased slightly compared to the 2020 emission reduction targets case. When emission reduction targets increase from $20 \%$ to $25 \%$, total output, $W, C S, P S$, and emission loss decrease by $0.09 \%,-0.07 \%, 0.18 \%,-0.50 \%$, and $6.33 \%$, respectively.

For the sub-region, to achieve the emission mitigation target of $20 \%-25 \%$, enterprises in each region choose the emission intensity and output. When the emission reduction targets gradually increased, the rate of decline in emission reduction intensity in various regions has gradually increased. In Southwest and Northwest China, the emission reduction rate has exceeded $20 \%$ in most cases. When the industry emission reduction target is $25 \%$, the emission reduction rate in the northwest region has reaches the maximum, which is $41.48 \%$, in East China and North China. When the emission range is in the middle, the decline range is about $13 \%-19 \%$. The emission reduction range in the Northeast and South Central regions is small, and, in the Northeast, it is the smallest. Along with the effects of carbon trading policies and subsidies, the output changes show great regional differences. The output of North China, East China, South Central, and Southwest China present an upward trend; steel production in Northeast China and Northwest China show a downward trend, with a drop of $2.5 \%-3 \%$.

Under the premise emission reduction target of $20 \%-25 \%$ and 2.3782 tons $\mathrm{CO}_{2} /$ ton steel as the carbon trading benchmark value, only the North China $\mathrm{CO}_{2}$ emission intensity is lower than the benchmark value, and the enterprise can choose to sell its own carbon quotas; $\mathrm{CO}_{2}$ emission intensity in other regions cannot be lower than the benchmark level, and carbon quotas need to be purchased. In addition, the government (steel industry) needs to return subsidies based on production to these regions.

\subsubsection{Case 3, in 2030 Scenario}

The mixed emission mitigation policies cover carbon trading policy, subsidies, and government-funded CCS demonstration projects. The results are shown in Figures 6 and 7, Tables 8 and 9. Due to the strict emission benchmark values, the $\mathrm{CO}_{2}$ emission intensity of some regional enterprises cannot meet or fall below the benchmark value. The government needs to provide subsidies for enterprises with higher emission intensity. As the emission reduction target increases from $25 \%$ to $30 \%$, the transaction price of carbon emission allowance increases from 91.70 yuan/ton to 137.59 yuan/ton—an increase of 1.79 times. The unit subsidy value is maintained at around $30-36$ yuan; the $\mathrm{CO}_{2}$ processed by the government-funded CCS demonstration project are always at the lowest value, $m=1,000,000$ ton.

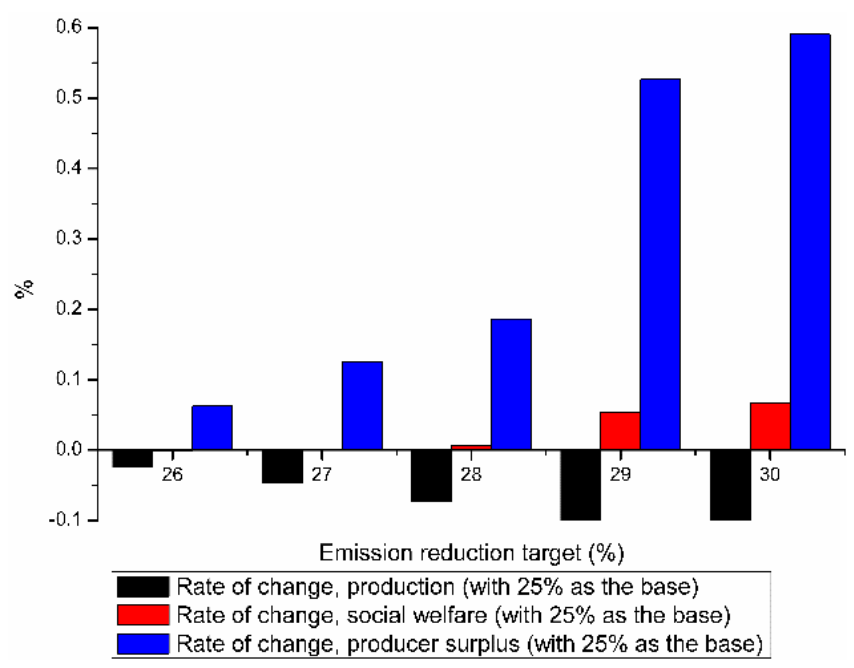

Figure 6. The rate of change of output, social welfare and producer surplus under the carbon trading mechanism; take $25 \%$ as the baseline. 


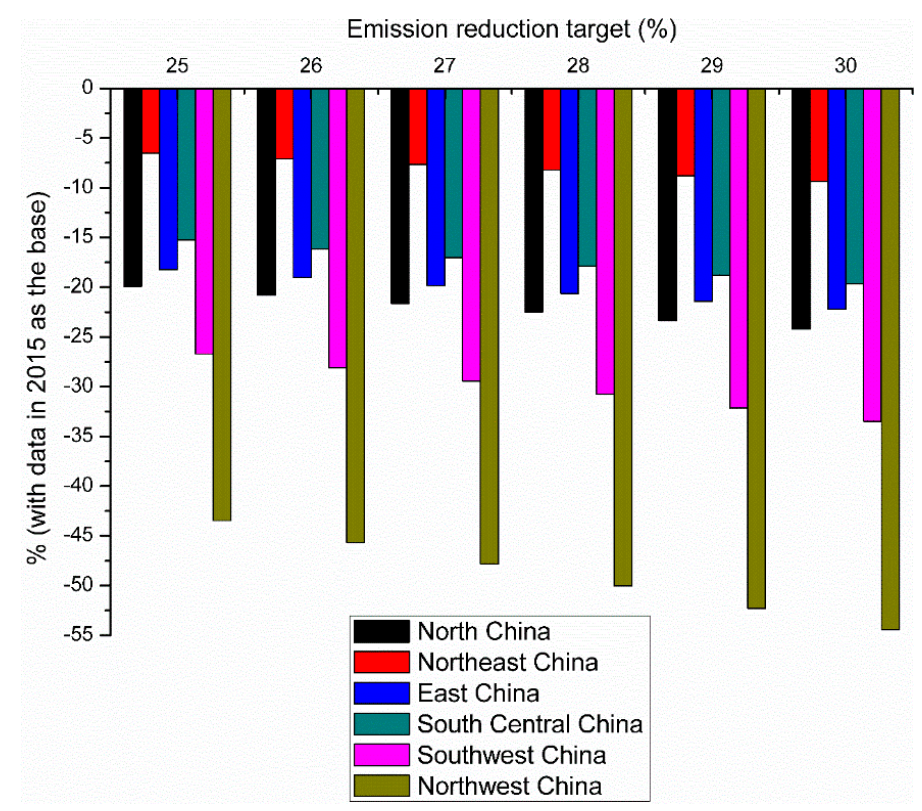

Figure 7. The change of regional emission intensity with the overall emission reduction target (25\%-30\%, carbon trade + subsidy + carbon capture and storage (CCS)).

Table 8. The changes of the overall industry indicators under the carbon trade mechanism; the emission reduction target is $25 \%-30 \%$.

\begin{tabular}{ccccccc}
\hline Emission Reduction Target & $\mathbf{2 5 \%}$ & $\mathbf{2 6 \%}$ & $\mathbf{2 7 \%}$ & $\mathbf{2 8 \%}$ & $\mathbf{2 9} \%$ & $\mathbf{3 0} \%$ \\
\hline Carbon quota transaction price (Yuan) & 91.70 & 100.24 & 108.95 & 117.98 & 127.83 & 137.59 \\
Carbon quota transaction price (Yuan) & 9.3391 & 9.3368 & 9.3348 & 9.3323 & 9.3283 & 9.3274 \\
Unit value of subsidy (Yuan) & 30.5 & 29.5 & 28.5 & 26.5 & 36.5 & 36 \\
Rate of change, production (with 25\% as the base) & - & $-0.02 \%$ & $-0.05 \%$ & $-0.07 \%$ & $-0.12 \%$ & $-0.13 \%$ \\
Rate of change, social welfare (with 25\% as the base) & - & $0.00 \%$ & $0.00 \%$ & $0.01 \%$ & $0.05 \%$ & $0.07 \%$ \\
Rate of change, producer surplus (with 25\% as the base) & - & $0.06 \%$ & $0.12 \%$ & $0.19 \%$ & $0.53 \%$ & $0.59 \%$ \\
\hline
\end{tabular}

Table 9. The changes of the various region enterprise indicators under the carbon trade mechanism; the emission reduction target is $25 \%-30 \%$.

\begin{tabular}{|c|c|c|c|c|c|c|c|}
\hline \multicolumn{2}{|c|}{ Emission Reduction Target } & \multirow{2}{*}{$\begin{array}{c}\mathbf{2 5 \%} \\
2.3949\end{array}$} & \multirow{2}{*}{$\begin{array}{c}\mathbf{2 6 \%} \\
2.3974\end{array}$} & \multirow{2}{*}{$\begin{array}{c}\mathbf{2 7 \%} \\
2.3999\end{array}$} & \multirow{2}{*}{$\begin{array}{c}\mathbf{2 8 \%} \\
2.4024\end{array}$} & \multirow{2}{*}{$\begin{array}{c}\mathbf{2 9} \% \\
2.4049\end{array}$} & \multirow{2}{*}{$\begin{array}{c}30 \% \\
2.4078\end{array}$} \\
\hline \multirow{6}{*}{$\begin{array}{l}\text { Production (100 } \\
\text { million tons) }\end{array}$} & North China & & & & & & \\
\hline & Northeast China & 1.0483 & 1.0449 & 1.0413 & 1.0377 & 1.0341 & 1.0302 \\
\hline & East China & 2.1003 & 2.1005 & 2.1007 & 2.1008 & 2.1009 & 2.1009 \\
\hline & South Central China & 1.7343 & 1.7342 & 1.7342 & 1.7341 & 1.7339 & 1.7337 \\
\hline & Southwest China & 1.3864 & 1.3866 & 1.3869 & 1.3872 & 1.3875 & 1.3877 \\
\hline & Northwest China & 0.6749 & 0.6743 & 0.6739 & 0.6736 & 0.6734 & 0.6732 \\
\hline \multirow{6}{*}{$\begin{array}{l}\text { Rate of change, } \\
\text { production (with } 25 \% \\
\text { as the base) }\end{array}$} & North China & - & $0.21 \%$ & $0.42 \%$ & $0.66 \%$ & $0.97 \%$ & $1.17 \%$ \\
\hline & Northeast China & - & $-0.66 \%$ & $-1.35 \%$ & $-2.10 \%$ & $-1.75 \%$ & $-2.54 \%$ \\
\hline & East China & - & $0.02 \%$ & $0.03 \%$ & $0.03 \%$ & $0.60 \%$ & $0.61 \%$ \\
\hline & South Central China & - & $-0.01 \%$ & $-0.02 \%$ & $-0.05 \%$ & $0.62 \%$ & $0.60 \%$ \\
\hline & Southwest China & - & $0.04 \%$ & & $0.11 \%$ & $-1.28 \%$ & $-1.18 \%$ \\
\hline & Northwest China & - & $-0.15 \%$ & $-0.23 \%$ & $-0.27 \%$ & $-3.18 \%$ & $-2.94 \%$ \\
\hline \multirow{6}{*}{$\begin{array}{l}\text { The decline range of } \\
\text { emission intensity } \\
\text { (with data in } 2015 \text { as } \\
\text { the base) }\end{array}$} & North China & $-19.90 \%$ & $-20.77 \%$ & $-21.62 \%$ & $-22.47 \%$ & $-23.36 \%$ & $-24.21 \%$ \\
\hline & Northeast China & $-6.55 \%$ & $-7.09 \%$ & $-7.63 \%$ & $-8.19 \%$ & $-8.79 \%$ & $-9.37 \%$ \\
\hline & East China & $-18.24 \%$ & $-19.04 \%$ & $-19.83 \%$ & $-20.62 \%$ & $-21.44 \%$ & $-22.22 \%$ \\
\hline & South Central China & $-15.26 \%$ & $-16.14 \%$ & $-17.01 \%$ & $-17.88 \%$ & $-18.79 \%$ & $-19.66 \%$ \\
\hline & Southwest China & $-26.71 \%$ & $-28.08 \%$ & $-29.42 \%$ & $-30.76 \%$ & $-32.16 \%$ & $-33.50^{\circ}$ \\
\hline & Northwest China & $-43.45 \%$ & $-45.68 \%$ & $-47.85 \%$ & $-50.01 \%$ & $-52.27 \%$ & $-54.44^{\circ}$ \\
\hline
\end{tabular}


When the emission reduction targets gradually increase from $25 \%$ to $30 \%$, the total output, consumer surplus, and macro-environmental losses caused by $\mathrm{CO}_{2}$ emissions have decreased, and the overall social welfare and producer surplus have shown an upward trend. This suggests that, although the emission reduction target becomes increasingly severe, the behavior of returning subsidies to enterprises has increased the production enthusiasm of producers and helps to increase corporate profits. The total output has remained at around 933 million tons. Though the emission reduction target has increased, the total output has increased slightly compared to the 2025 emission reduction targets case. Total output, $W, C S, P S$, and emission loss decreased by $0.13 \%,-0.07 \%, 0.25 \%,-0.59 \%$, and $6.81 \%$, respectively.

For the sub-region, as the emission reduction target increases, and the rate of decline in emission reduction intensity in various regions has gradually increased. In most cases in Southwest China and Northwest China, the emission intensity decrease exceeded 30\%. When the overall emission reduction target is 30\%, the Northwest region's reduction rate reaches the maximum, which is $54.43 \%$. In North China, East China, and South Central China, the emission reduction rate is in the middle; the rate in the Northeast is the smallest. Along with the effects of mixed carbon trading policies, the output changes show great regional differences. In North China, East China, and South Central China, it showed an upward trend; the output of steel in Northeast China, Southwest China, and Northwest China show a downward trend.

Under the premise emission reduction target of $25 \%-30 \%$ and 2.2197 tons $\mathrm{CO}_{2} /$ ton steel as the carbon trading benchmark value, only the North China $\mathrm{CO}_{2}$ emission intensity is lower than the benchmark value, and the enterprise can choose to sell its own carbon quotas. $\mathrm{CO}_{2}$ emission intensity in other regions cannot be lower than the benchmark value under most emission reduction targets; they need to purchase carbon quotas, and the government (steel industry) needs to return subsidies based on production. When the target is high (29\%-30\%), the $\mathrm{CO}_{2}$ emission intensity in Southwest China and Northwest China is slightly lower than the benchmark value, so they can choose to sell their carbon quotas.

\subsubsection{Comparison of Single Emission Reduction Policies and Mixed Emission Reduction Policies}

Sections 4.2.2 and 4.2.3 discuss the impact of the implementation of the mixed emission reduction policy on the changes in the economic and environmental factors of steel companies and industries under the carbon trading mechanism. This section calculates the changes in the output and emission reduction intensity of enterprises and other economic factors in the implementation of the single policy under the same emission reduction targets, then compares and analyzes the single and mixed emission reduction policy.

(1) Comparison of only carbon trading policies and mixed policies in 2025.

After calculation and as shown in Table 10, Figures 8-10, the social welfare, total output, producer surplus, consumer surplus, carbon allowance transaction price, and the macro environmental damage caused by $\mathrm{CO}_{2}$ emissions and the decline in $\mathrm{CO}_{2}$ emission intensity under the mixed policy mechanism in various regions have increased more than that under the situation of the single policy. Under the mixed policy mechanism, the carbon price trading price and the regional emission intensity decrease than that in the single policy mechanism, but the gap is negligibly small.

Table 10. The indicators change under the carbon trade mechanism; the target in single policy is $20 \%$ to $25 \%$.

\begin{tabular}{cllllll}
\hline Emission Reduction Target & $\mathbf{2 0} \%$ & $\mathbf{2 1 \%}$ & $\mathbf{2 2 \%}$ & $\mathbf{2 3 \%}$ & $\mathbf{2 4 \%}$ & $\mathbf{2 5 \%}$ \\
\hline Carbon quota transaction price (Yuan) & 46.91 & 53.54 & 60.59 & 68.03 & 75.88 & 84.12 \\
Production (100 million tons) & 9.0066 & 9.0049 & 9.0033 & 9.0019 & 9.0006 & 8.9995 \\
Rate of change, production (with 20\% as the base) & - & $-0.02 \%$ & $-0.04 \%$ & $-0.05 \%$ & $-0.07 \%$ & $-0.08 \%$ \\
Rate of change, social welfare (with 20\% as the base) & - & $0.01 \%$ & $0.02 \%$ & $0.03 \%$ & $0.05 \%$ & $0.07 \%$ \\
Rate of change, producer surplus (with 20\% as the base) & - & $0.09 \%$ & $0.19 \%$ & $0.29 \%$ & $0.40 \%$ & $0.50 \%$ \\
\hline
\end{tabular}




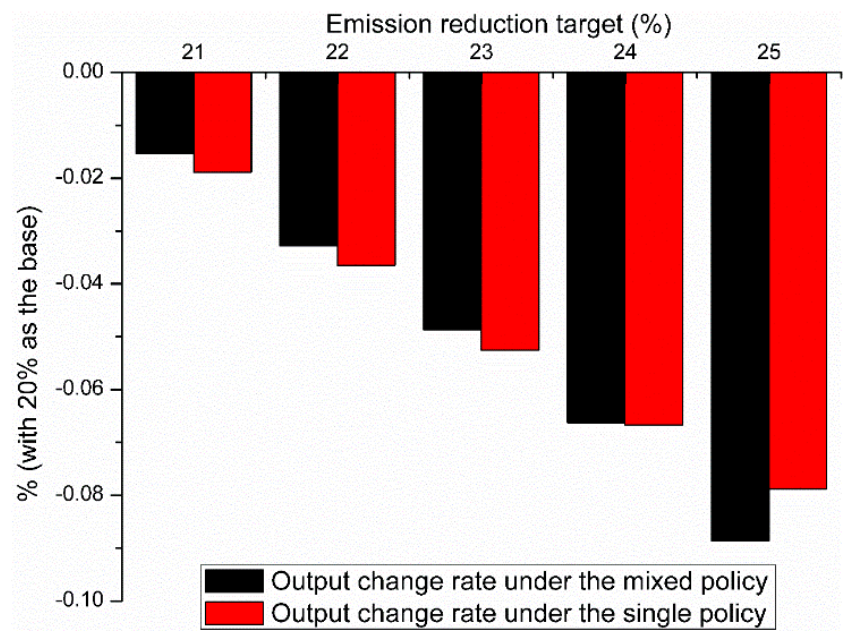

Figure 8. The output change rate compared under the single policy and the mixed policy in the carbon trade mechanism; take $20 \%$ as the baseline.

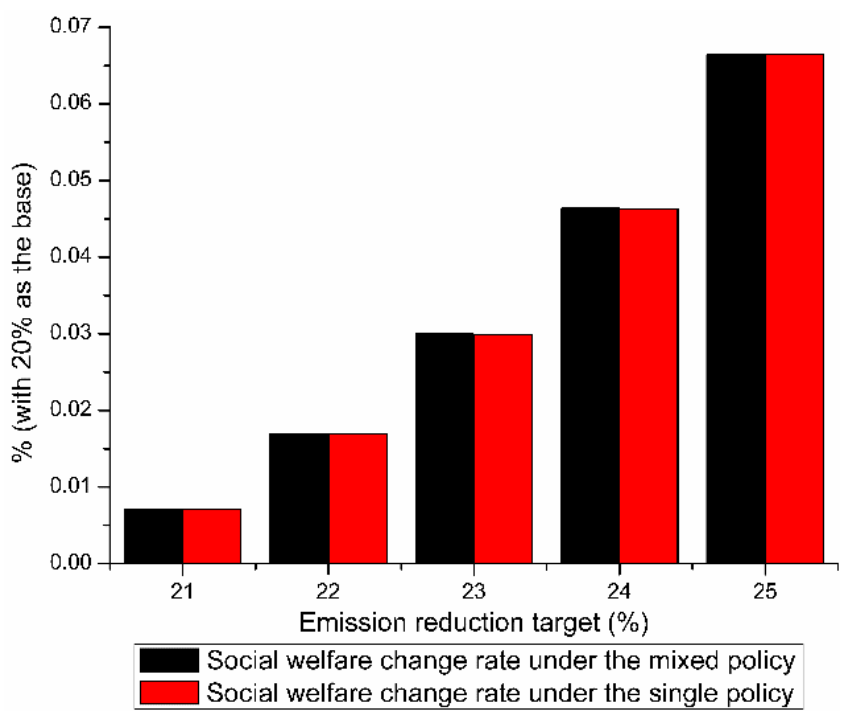

Figure 9. The social welfare change rate compared under the single policy and the mixed policy in the carbon trade mechanism; take $20 \%$ as the baseline.

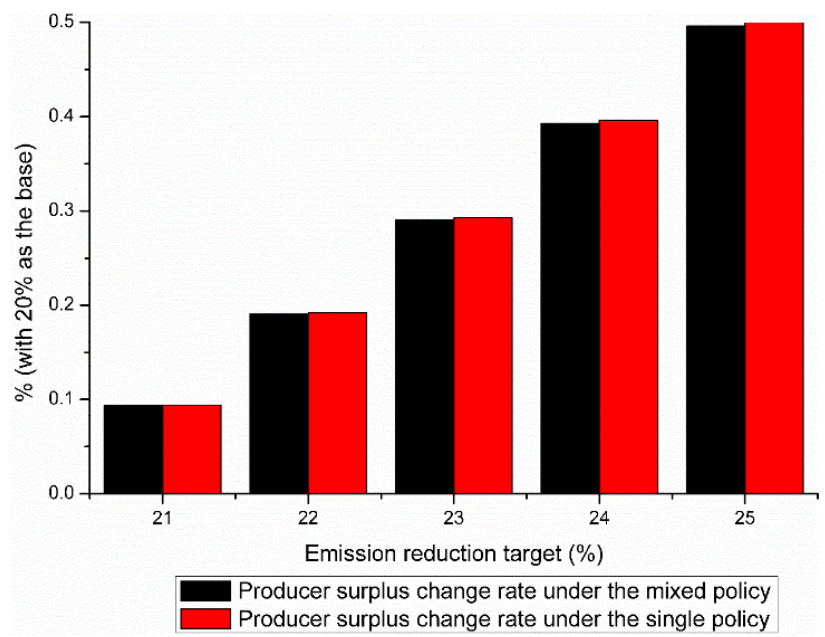

Figure 10. The producer surplus change rate compared under the single policy and the mixed policy in the carbon trade mechanism; take $20 \%$ as the baseline. 
The rate of change reflects the intensity of changes in various indicators as the emission reduction target increases (compared to $20 \%$ reduction in 2010). From the figures, it can be found that in production change rates when emission reduction targets are low $(20 \%-24 \%)$, steel production under a single policy changes significantly. When emission reduction targets are high $(24 \%-25 \%)$, the change of steel production under the mixed policy is more obvious. In the change rate of producer surplus and social welfare, the two policy conditions are basically flat, and the single policy changes slightly larger.

(2) Comparison of only carbon trading policies and mixed policies in 2030.

Calculations have found that in the case of emission reduction targets of $25 \%-30 \%$, the $\mathrm{CO}_{2}$ emissions processed by CCS demonstration projects are at the lowest value; that is, under each emission reduction target, the CCS demonstration project is only at the lowest maintenance stage.

Similarly, after calculation and as shown in Table 11, Figures 11-13, the social welfare, total output, producer surplus, consumer surplus, carbon allowance transaction price, and the macro environmental damage caused by $\mathrm{CO}_{2}$ emissions and the decline in $\mathrm{CO}_{2}$ emission intensity under the mixed policy mechanism in various regions have increased more than that under the situation of the single policy. Under the mixed policy mechanism, the carbon price trading price and the regional emission intensity decrease more than that in the single policy mechanism, but the gap is so small that they can be ignored.

Table 11. The indicators change under the carbon trade mechanism; the target in single policy is $25 \%$ to $30 \%$.

\begin{tabular}{ccccccc}
\hline Emission Reduction Target & $\mathbf{2 5 \%}$ & $\mathbf{2 6 \%}$ & $\mathbf{2 7 \%}$ & $\mathbf{2 8 \%}$ & $\mathbf{2 9 \%}$ & $\mathbf{3 0} \%$ \\
\hline Carbon quota transaction price (Yuan) & 91.17 & 99.72 & 108.45 & 117.51 & 126.89 & 136.59 \\
Production (100 million tons) & 9.3200 & 9.3183 & 9.3168 & 9.3156 & 9.3146 & 9.3138 \\
Rate of change, production (with 25\% as the base) & - & $-0.02 \%$ & $-0.03 \%$ & $-0.05 \%$ & $-0.06 \%$ & $-0.07 \%$ \\
Rate of change, social welfare (with 25\% as the base) & - & $0.00 \%$ & $0.00 \%$ & $0.01 \%$ & $0.02 \%$ & $0.03 \%$ \\
Rate of change, producer surplus (with 25\% as the base) & - & $0.07 \%$ & $0.13 \%$ & $0.20 \%$ & $0.27 \%$ & $0.34 \%$ \\
\hline
\end{tabular}

The rate of change reflects the intensity of changes in various indicators as the emission reduction target increases (compared to $25 \%$ reduction in 2010). From the figures, it can be found that in production change rate, the effect of implementing a single policy on output change is significantly less than the impact of the implementation of the mixed policy. In the change rate of $W$ and PS, when emission reduction targets are low $(26 \%-28 \%)$, change rates are basically flat under the two policy conditions and slightly larger under a single policy. When emission reduction targets are higher $(28 \%-30 \%)$, changes under mixed policies are more pronounced.

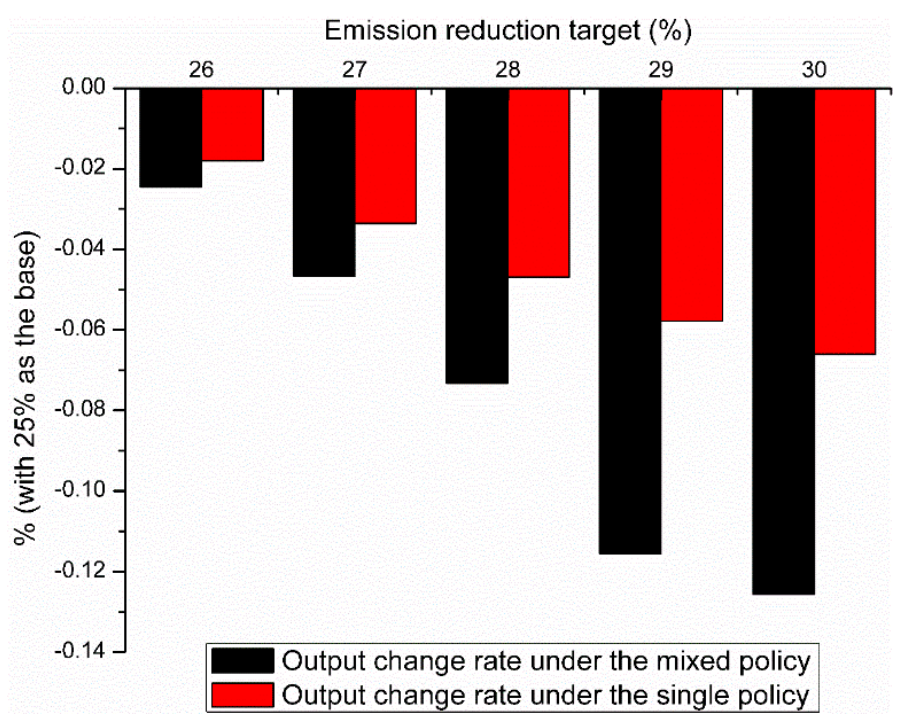

Figure 11. The output change rate compared under the single policy and the mixed policy in the carbon trade mechanism; take $25 \%$ as the baseline. 


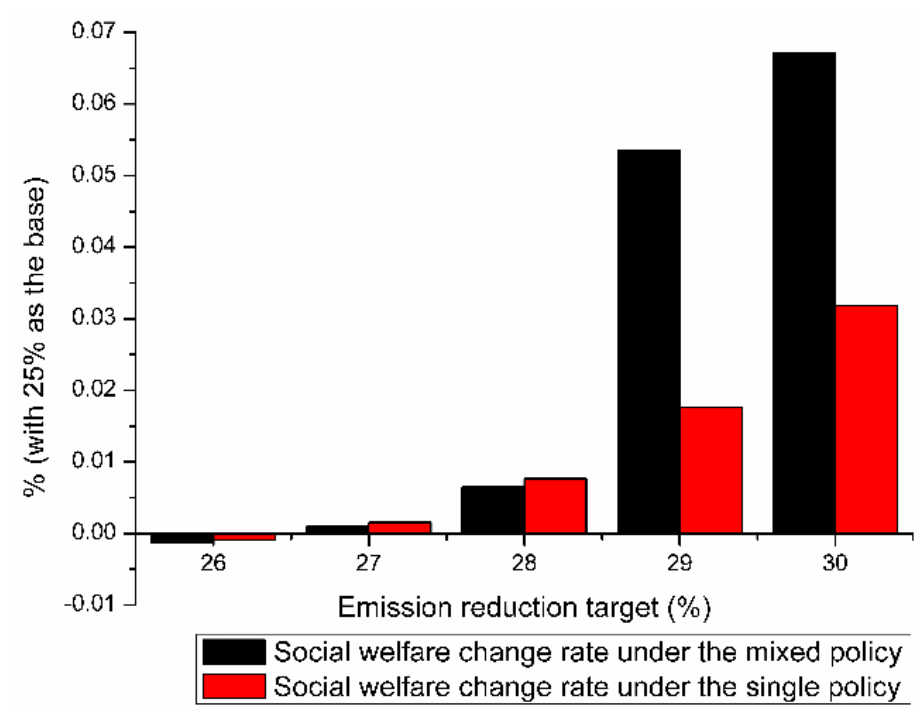

Figure 12. The social welfare change rate compared under the single policy and the mixed policy in the carbon trade mechanism; take $25 \%$ as the baseline.

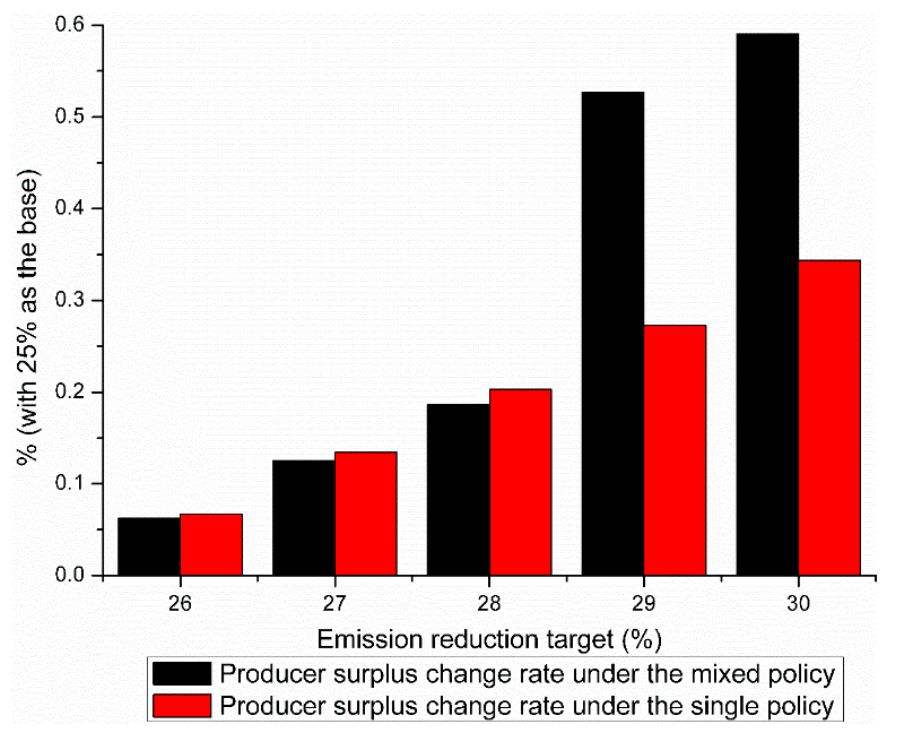

Figure 13. The producer surplus change rate compared under the single policy and the mixed policy in the carbon trade mechanism; take $25 \%$ as the baseline.

\subsection{Discussions}

Current research on the emissions mitigation targets is scarce. Therefore, this paper does not discuss optimal emissions intensity and methods. Only the above three scenarios $(2020,2025,2030)$ have been analyzed. For China's industrial sector, the results of parameters and numerical calculations are few and lack certain references. Since the country has not announced the relevant details and trading methods of the carbon trading market, the carbon trading benchmark value is set based on the historical data. Moreover, due to these certain assumptions, there are some gaps between the calculations results and the actual situation, but some trends and rules can still be found and determined.

Since the carbon trading mechanism is based on the government's provision of a free carbon quota for each company, the benchmarks are set differently, and the results will vary. Under the conditions set in this paper, whether under the single carbon trading policy or the mixed policy, when the reduction target increases from $15 \%$ to $30 \%$, the quota trading price steadily increases from 12.65 Yuan to about 137 Yuan (nearly 11 times), and the social welfare and producer surplus of the steel industry show an increasing trend-nearly $14 \%$ and $4 \%$, respectively. While the macro-loss of $\mathrm{CO}_{2}$ emissions shows 
a decreasing trend (decrease by more than 10\%), other indicators increase or decrease. This shows that from the perspective of the implementation of the policy, the carbon trading policy and the mix with other emission reduction policies are conducive to the improvement of the economic level and emission reduction level of the steel industry.

For the sub-region, when the $\mathrm{CO}_{2}$ emission reduction target gradually increases, the regional emission reduction pressure gradually increases as well. However, there are differences between regions. The decline range in emission reductions in Northwest China and Southwest China is much bigger than other four regions, and the range in the northeast region is the smallest.

Under the mixed policy mechanism, compared with the single carbon trading policy, the social welfare function, total output, producer surplus, consumer surplus, carbon quota trading price, macro-loss caused by $\mathrm{CO}_{2}$ emissions, and emission reductions of the entire steel industry improve. Though under the same emission reduction target, the carbon allowance trading price in the single policy is less than that in the mixed policy, and the decline range in regional emissions reduction in the single policy is also lower than that under the mixed policies (though it is almost negligible-no more than 1 Yuan and 0.01 ton $\mathrm{CO}_{2}$ /ton). Therefore, under the carbon trading mechanism, it is necessary to comprehensively consider the balance between the whole industry and regions and to consider whether to use a single carbon trading mechanism or a mixed mechanism under the comprehensive evaluation.

Through numerical simulation, when the benchmark values in 2020, 2025, and 2030 are 2.8210 tons of $\mathrm{CO}_{2} /$ ton steel, 2.3782 tons of $\mathrm{CO}_{2} /$ ton steel, and 2.2197 tons of $\mathrm{CO}_{2} /$ ton steel, respectively, China's future steel output will be in the range of 854-934 million tons under the mixed policy mechanism. The carbon price trading price range is between 12.65-137.59 yuan. The subsidy unit value ranges from 15.5-36.5 yuan. The CCS demonstration projects are only in the minimum maintenance stage and have not played a significant role in social emission reduction. Under the single carbon trading policy, the future steel output will be in the range of 854-932 million tons, and the price of carbon trading quotas will be between 12.65 and 136.59 yuan.

Obviously, whether it is a single carbon trading policy or a mixed policy, when the market is balanced, the output is reduced by more than 200 million tons from the peak in 2016 (1.1346 billion tons). North China and East China have decreased a lot, while the northeast, southwest, and northwest regions have increased in production. This shows that the implementation of carbon trading policies and mixed policies have alleviated the polarization of production in various regions to some extent, which is conducive to optimizing the distribution of production between regions and enterprises so that enterprises can better achieve the best profit.

\section{Conclusions}

Through the introduction of carbon trading policy, subsidy policy, CCS, and other emission reduction policies, a two-stage multi-oligopoly enterprise production selection model including emission reduction policies is established. This paper makes a preliminary study on the changes of total production and social welfare indexes, which are under the restriction of the industry emission reduction target and emission reduction policy, and carries on the quantitative research with the operation data of iron and steel industry. The model is an abstraction and hypothesis of a practical problem, which causes the calculation results in this paper to potentially deviate a little from the actual situation. This paper emphasizes the change trends of corresponding indicators with the increase of governmental pressure on emissions reduction.

The main conclusions are as follows:

Under the carbon trading policy mechanism, the carbon quota trading price increases as the reduction targets increase, and the steel industry social welfare and producer surplus show an increasing trend. The $\mathrm{CO}_{2}$ emission macro loss shows a decreasing trend, and the other indexes increase or decrease. When the emission reduction targets gradually increase, the pressure on emission reduction among regional oligarchic enterprises also gradually increases. The emission reduction rate of oligarchs in Northwest and Southwest China is much bigger than that in other regions. Oligarchy enterprises in 
North China, East China and South Central China are second. Oligopolistic enterprises in Northeast China are the lowest. Since the benchmark values are set differently, the numerical results will be different, but the trends are basically similar.

Compared with the single carbon trading policy, the indicators under the mixed policy have increased. In the view of change rate in production, social welfare, and producer surplus, when under the lower emission reduction target, the change under a single policy is greater; when under the higher target, change caused by the mixed policy is more obvious.

Based on the above results and conclusions, the Chinese steel industry should focus on the following two aspects when formulating emission mitigation targets and auxiliary emission mitigation policies:

Firstly, the Chinese iron and steel industry at present is in the stage of excess production capacity, which means that the output capacity is far greater than the actual consumption level. Through the calculation of this paper, when the market reaches the equilibrium, the production and consumption are less than the present level, especially in 2016. As a result, for China's iron and steel industry (government) should alleviate the contradiction of excess production capacity and bring relief to the industry. It is immediate and necessary for the government to ban new production and push obsolete and backward-producing enterprises out of the market as soon as possible.

Secondly, at present, there is no clear-text regulation of the use conditions and industry scope of carbon trading policies in China. This paper uses the benchmark method to conduct a preliminary study on the carbon trading mechanism of the steel industry. In combination with the actual situation, we propose that in the use of single and mixed emission reduction policies under the carbon trading mechanism, the government should consider the whole industry sector, regional balance, and carbon trading benchmarks to determine the implementation of a single or mixed carbon trading policy. In the selection of the carbon trading benchmark value, it is necessary to carefully select according to the emission reduction target and the requirements for economic indicators.

This paper conducted a preliminary study on the carbon trade mechanism. With the gradual improvement of relevant national policies, laws, and regulations, this study will continue to explore the details of the carbon trading market of the steel industry and the game behavior between enterprises. Future research will be more closely linked to national policies and will be gradually extended to other high-energy industries such as cement industry and chemical industry.

Author Contributions: Both authors contributed equally to this work. In particular, H.M. and Y.D. had the original idea for the study, and both coauthors conceived of and designed the methodology. Y.D. drafted the manuscript, which was revised by Z.H., J.Y. and Y.L. All authors have read and approved the final manuscript.

Funding: This research was funded by the National Natural Science Foundation of China $(41571122,41771178)$.

Acknowledgments: The authors are grateful to the editor and anonymous referees who provided valuable comments and suggestions to significantly improve the quality of the paper.

Conflicts of Interest: The authors declare no conflict of interest.

\section{References}

1. Dales, J.H. Pollution, Property E Prices: An Essay in Policy-Making and Economics; Edward Elgar Publishing: Cheltenham, UK, 1968.

2. Li, J.; Colombier, M. Managing carbon emissions in China through building energy efficiency. J. Environ. Manag. 2009, 90, 2436-2447. [CrossRef] [PubMed]

3. Anger, A. Including aviation in the European emissions trading scheme: Impacts on the industry, $\mathrm{CO}$ emissions and macroeconomic activity in the EU. J. Air Transp. Manag. 2010, 16, 100-105. [CrossRef]

4. Chen, Y.; Tseng, C.L. Climate Policies and the Power Sector: Challenges and Issues. J. Energy Eng. 2008, 134, 31-32. [CrossRef]

5. Alberola, E.; Chevallier, J.; Chèze, B. Emissions Compliances and Carbon Prices under the EU ETS: A Country Specific Analysis of Industrial Sectors. J. Policy Model. 2009, 31, 446-462. [CrossRef]

6. Considine, T.; Larson, D.F. Short term electric production technology switching under carbon cap and trade. Energies 2012, 5, 4165-4185. [CrossRef] 
7. Shen, L.; Song, X.; Wu, Y.; Liao, S.; Zhang, X. Interpretive Structural Modeling based factor analysis on the implementation of Emission Trading System in the Chinese building sector. J. Clean. Prod. 2016, 127, 214-227. [CrossRef]

8. $\mathrm{Su}, \mathrm{L}$. The Research on Transportaition Network Model Considering the Cap and Trade Policy. Master's Thesis, Beijing University of Chemical Technology, Beijing, China, 2017.

9. Zhang, Q. Impact Assessment of Carbon Trading System on the Construction Industry: Based on CGE Model. Master's Thesis, Chongqing University, Chongqing, China, 2017.

10. Ahman, M.; Zetterberg, L. Options for emission allowance allocation under the Eu Emissions Trading Directive. Mitig. Adapt. Strateg. Glob. Chang. 2007, 12, 1433. [CrossRef]

11. Goeree, J.K.; Palmer, K.; Holt, C.A.; Shobe, W.; Burtraw, D. An Experimental Study of Auctions Versus Grandfathering to Assign Pollution Permits. J. Eur. Econ. Assoc. 2010, 8, 514-525. [CrossRef]

12. Zetterberg, L.; Wråke, M.; Sterner, T.; Fischer, C.; Burtraw, D. Short-Run Allocation of Emissions Allowances and Long-Term Goals for Climate Policy. Ambio 2012, 41, 23-32. [CrossRef] [PubMed]

13. Grimm, V.; Ilieva, L. An experiment on emissions trading: The effect of different allocation mechanisms. J. Regul. Econ. 2013, 44, 308-338. [CrossRef]

14. Wang, J.; Wang, Y.Y. Study on the Initial Allocation Means of the Carbon Emission Rights in Beijing and International Experience Learning. J. Beijing Univ. Technol. 2014, 14, 19-26.

15. Lee, J.; Yu, J. Market Analysis during the First Year of Korea Emission Trading Scheme. Energies 2017, 10, 1974. [CrossRef]

16. Guo, D.Y.; Chen, H.; Long, R.Y. The allocation strategy of government for initial carbon allowance in downstream carbon trading market. China Popul. Resour. Environ. 2018, 28, 43-54.

17. Zhang, L.; Li, Y.; Jia, Z. Impact of carbon allowance allocation on power industry in China's carbon trading market: Computable general equilibrium based analysis. Appl. Energy 2018, 229, 814-827. [CrossRef]

18. Duscha, V. The EU ETS and Dynamic Allocation in Phase IV-An Ex-Ante Assessment. Energies 2018, 11, 409. [CrossRef]

19. Chen, W.Y.; Wu, Z.X. Carbon emission permit allocation and trading. J. Tsinghua Univ. 1998, 38, 15-18, 22.

20. Ellerman, A.D.; Jacoby, H.D.; Decaux, A. The Effects on Developing Countries of the Kyoto Protocol and Carbon Dioxide Emissions Trading; The World Bank Development Research Group: Washington, DC, USA, 1998.

21. Babiker, M.; Reilly, J.; Viguier, L. Is International Emissions Trading Always Beneficial? Energy J. 2004, 25, 33-56. [CrossRef]

22. Wang, C.; Chen, J.N.; Zou, J. Potential analysis of clean development mechanism put into effect in China. China Environ. Sci. 2005, 25, 310-314.

23. Jamasb, T.; Kohler, J. Learning Curves for Energy Technology: A Critical Assessment; Cambridge Univ., 2007; Available online: https://www.repository.cam.ac.uk/bitstream/handle/1810/194736/0752\%26EPRG0723.pdf? sequence $=1 \&$ is Allowed $=y$ (accessed on 31 October 2007).

24. Aviyonah, R.S.; Uhlmann, D.M. Combating Global Climate Change: Why a Carbon Tax is a Better Response to Global Warming than Cap and Trade. Stanf. Environ. Law J. 2009, 28, 3-50.

25. Cong, R.G.; Wei, Y.M. Potential impact of (CET) carbon emissions trading on China's power sector: A perspective from different allowance allocation options. Energy 2010, 35, 3921-3931. [CrossRef]

26. Wu, J.; Fan, Y.; Xia, Y.; Liu, J.Y. Impacts of Initial Quota Allocation on Regional Macro-economy and Industry Competitiveness. Manag. Rev. 2015, 27, 18-26.

27. Li, Y.; Zhu, L. Impacts of ETS on Elimination of Backward Production Capacity in Energy-intensive Industries. Green Pet. Petrochem. 2017, 2, 6-15.

28. Wu, J.; Fan, Y.; Xia, Y. How can China achieve its nationally determined contribution targets combining emissions trading scheme and renewable energy policies? Energies 2017, 10, 1166. [CrossRef]

29. Dai, H.; Xie, Y.; Liu, J.; Masui, T. Aligning renewable energy targets with carbon emissions trading to achieve China's INDCs: A general equilibrium assessment. Renew. Sustain. Energy Rev. 2018, 82, 4121-4131. [CrossRef]

30. Liu, Y.P.; Gao, X.Y.; Guo, J.F. Network Features of the EU Carbon Trade System: An Evolutionary Perspective. Energies 2018, 11, 1501. [CrossRef]

31. Fernández Fernández, Y.; Fernández López, M.A.; González Hernández, D.; Olmedillas Blanco, B. Institutional Change and Environment: Lessons from the European Emission Trading System. Energies 2018, 11, 706. [CrossRef] 
32. Mann, R.F. The Case for the Carbon Tax: How to Overcome Politics and Find Our Green Destiny. Environ. Law Rep. 2009, 39, 10118-10126.

33. Wang, W.J.; Xie, P.C.; Hu, J.L.; Wang, L.; Zhao, D.Q. Analysis of the Relative Mitigation Cost Advantages of Carbon Tax and ETS for the Cement Industry. Clim. Chang. Res. 2016, 12, 53-60.

34. Duan, Y.; Li, N.; Mu, H.L.; Gui, S.S. Research on $\mathrm{CO}_{2}$ Emission Reduction Mechanism of China's Iron and Steel Industry under Various Emission Reduction Policies. Energies 2017, 10, 2026. [CrossRef]

35. National Bureau of Statistics of the People's Republic of China. CSY, 2005-2017. China Statistical Yearbook; National Bureau of Statistics of the People's Republic of China: Beijing, China, 2005-2017.

36. National Bureau of Statistics of the People's Republic of China. CIESY, 2005-2017. China Industrial Statistical Yearbook; National Bureau of Statistics of the People's Republic of China: Beijing, China, 2005-2017.

37. National Bureau of Statistics of the People's Republic of China. CESY, 2005-2017. China Energy Statistical Yearbook; National Bureau of Statistics of the People's Republic of China: Beijing, China, 2005-2017.

38. The Editorial Board of China Steel Yearbook. CSY, 2005-2017. China Steel Yearbook; The Editorial Board of China Steel Yearbook: Beijing, China, 2005-2017.

39. Intergovernmental Panel on Climate Change (IPCC). IPCC Guidelines for National Greenhouse Gas Inventories; United Kingdom Meteorological Office: Bracknell, UK, 2006.

40. Duan, Y.; Mu, H.L.; Li, N. Analysis of the Relationship between China's IPPU $\mathrm{CO}_{2}$ Emissions and the Industrial Economic Growth. Sustainability 2016, 8, 426. [CrossRef]

41. Ma, W.J.; Li, M.G. The Systemic Calculation of Optimal Concentration Degree in China's Iron and Steel Industry:Empirical Study Based on Double Efficiency Goals Pursued by Firms and Industry and the Data of 2007. J. Financ. Econ. 2011, 37, 104-113.

42. Duan, Y.; Li, N.; Mu, H.; Li, L.X. Research on Provincial Shadow Price of Carbon Dioxide in China's Iron and Steel Industry. Energy Procedia 2017, 142, 2335-2340. [CrossRef]

43. Färe, R.; Grosskopf, S.; Pasurka Jr, C.A. Environmental production functions and environmental directional distance functions. Energy 2007, 32, 1055-1066. [CrossRef]

44. Lee, J.D.; Park, J.B.; Kim, T.Y. Estimation of the shadow prices of pollutants with production/environment inefficiency taken into account: A nonparametric directional distance function approach. J. Environ. Manag. 2002, 64, 365-375. [CrossRef]

45. Li, C.S. Mechanism Design of Emission Tax Based on Dynamic Game Theory. Ph.D. Thesis, University of Science and Technology of China, Hefei, China, 2012.

46. Guenno, G.; Tiezzi, S. The Index of Sustainable Economics Welfare (ISEW) for Italy; Fondazione Eni Enrico Mattei: Milano, Italy, 1998.

47. Dahowski, R.T.; Li, X.; Davidson, C.L.; Wei, N.; Dooley, J.J.; Gentile, R.H. A preliminary cost curve assessment of carbon dioxide capture and storage potential in China. Energy Procedia 2009, 1, 2849-2856. [CrossRef]

48. Liu, H.; Gallagher, K.S. Preparing to ramp up large-scale CCS demonstrations: An engineering-economic assessment of $\mathrm{CO}_{2}$ pipeline transportation in China. Int. J. Greenh. Gas Control 2011, 5, 798-804. [CrossRef]

49. Zhu, L.; Fan, Y. Modeling the Investment of Coal-fired Power Plant Retrofit with CCS and Subsidy Policy Assessment. China Popul. Resour. Environ. 2014, 24, 99-105.

50. Wang, B.Q.; Li, H.Q.; Bao, W.J. A model of economy for overall process of $\mathrm{CO}_{2}$ capture and saline storage. CIESC J. 2012, 63, 894-903.

(C) 2019 by the authors. Licensee MDPI, Basel, Switzerland. This article is an open access article distributed under the terms and conditions of the Creative Commons Attribution (CC BY) license (http://creativecommons.org/licenses/by/4.0/). 